\title{
The Heat Shock Response and Chaperones/Heat Shock Proteins in Brain Tumors: Surface Expression, Release, and Possible Immune Consequences
}

\author{
Michael W. Graner, R. Ian Cumming, and Darell D. Bigner \\ The Preston Robert Tisch Brain Tumor Center, Department of Pathology, Duke University Medical Center, Durham, North Carolina 27710
}

\begin{abstract}
The heat shock response is a highly conserved "stress response" mechanism used by cells to protect themselves from potentially damaging insults. It often involves the upregulated expression of chaperone and heat shock proteins (HSPs) to prevent damage and aggregation at the proteome level. Like most cancers, brain tumor cells often overexpress chaperones/HSPs, probably because of the stressful atmosphere in which tumors reside, but also because of the benefits of HSP cytoprotection. However, the cellular dynamics and localization of HSPs in either stressed or unstressed conditions has not been studied extensively in brain tumor cells. We have examined the changes in HSP expression and in cell surface/extracellular localization of selected brain tumor cell lines under heat shock or normal environments. We herein report that brain tumor cell lines have considerable heat shock responses or already high constitutive HSP levels; that those cells express various HSPs, chaperones, and at least one cochaperone on their cell surfaces; and that HSPs may be released into the extracellular environment, possibly as exosome vesicular content. In studies with a murine astrocytoma cell line, heat shock dramatically reduces tumorigenicity, possibly by an immune mechanism. Additional evidence indicative of an HSP-driven immune response comes from immunization studies using tumor-derived chaperone protein vaccines, which lead to antigen-specific immune responses and reduced tumor burden in treated mice. The heat shock response and HSPs in brain tumor cells may represent an area of vulnerability in our attempts to treat these recalcitrant and deadly tumors.
\end{abstract}

Key words: brain tumors; chaperone/heat shock proteins; cell surface; extracellular; exosomes; immune response

\section{Introduction}

The heat shock response is a major evolutionarily conserved "stress response" mechanism (Lindquist and Craig, 1988; Gething and Sambrook, 1992). The response generally entails a decrease in translation of non-stress-related proteins accompanied by concurrent increases in transcription and translation of chaperones/heat shock proteins (HSPs). HSPs are molecular chaperones whose functions include assistance with native protein folding, maintenance of multiprotein complexes, intraorganellar protein shuttling, and degradation of senescent proteins. When cell stress leads to protein denaturation, HSPs stabilize developing non-native structures and prevent aggregate development. On release from stress, HSPs will again assist in protein refolding and salvage, as well as disaggregation of inappropriate protein collectives, and will promote the degradation of unrecoverable

\footnotetext{
Received March 9, 2007; accepted Aug. 15, 2007.

This work was supported by the Duke University Brain Cancer Specialized Programs of Research Excellence (SPORE) Grant 5 P50 CA108786-02, the SPORE Career Development Award, National Institute of Neurological Disorders and Stroke Grant SRC 5 P50 20023-21, the Pediatric Brain Tumor Foundation, the Southeast Brain Tumor Foundation, and the Brian Cless Research Foundation. We thank Dr. Vince Guerriero (University of Arizona, Tucson, AZ) for the HspBP1 antibody; Dr. Sara Miller of the Duke University Cancer Center EM facility for performing the electron microscopy; Shelley Davis, Emily Disney, Nichole Satterwhite, and Angelika Dechkovskaia for superb technical support; and Dr Wasi Khan for insightful discussions.

Correspondence should be addressed to Michael W. Graner, Pathology, The Preston Robert Tisch Brain Tumor Center, Duke University Medical Center, Box 3156, MSRB1, Durham, NC 27710. E-mail: michael.graner@duke.edu. DOI:10.1523/JNEUROSCI.3588-07.2007

Copyright $\odot 2007$ Society for Neuroscience 0270-6474/07/2711214-14\$15.00/0
}

proteins. These activities are typically regarded as intracellularly compartmentalized.

Tumors may be thought of as highly stressed collections of cells, based on their status as tissues experiencing hypoxia, $\mathrm{pH}$ imbalances, and altered metabolic and redox states with significant vascular needs (Edinger, 2005; Griguer et al., 2005, 2006; Harguindey et al., 2005; Graner and Bigner, 2006) and relatively unmanaged DNA synthesis checkpoints leading to heavy mutational load. Chaperones/HSPs provide tumors with a means of not only coping with these stresses via the cytoprotective activities of chaperones, but tumors apparently thrive with the assistance of upregulated chaperone expression and activity (Garrido et al., 2003; Kamal et al., 2004). Additionally, tumor cells may surface display or express HSPs, a phenomenon not seen in normal cells (Eustace and Jay, 2004; Radons and Multhoff, 2005; Schmitt et al., 2007). The exact nature and/or function of this localization remain unclear.

Human brain tumors also express high levels of many chaperone proteins/HSPs as gauged by immunohistochemistry (IHC) (for review, see Graner and Bigner, 2005; Kato et al., 1993, 2001). Our group has also observed high expression levels of the HSP70 family members by tissue microarray IHC, in which we have noted atypical expression patterns compared with normal tissues (M. W. Graner, unpublished observations). These unusual expression patterns prompted us to examine the dynamic ranges and locations of HSP expression in a number of brain tumor cell 
lines before and after heat shock. Our results demonstrate a substantial HSP production in the cell lines examined, either constitutive or stress responsive, along with HSP expression on tumor cell surfaces, which we believe is the first time this many different HSPs have been reported on brain tumor cells. There is also extracellular release of HSPs, either directly or resulting from exosome formation by the cell lines; again, the latter is a novel observation for brain tumor cells. Because there is also a widely noted correlation between surface/extracellular HSP expression and antitumor immune responses (Asea, 2005; Fleshner and Johnson, 2005; Schmitt et al., 2007), we studied the effects of heat stress on tumorigenicity in a syngeneic murine brain tumor. In this immune-competent model, HSP induction correlates with lack of tumorigenicity, which is likely because of immune responses against the tumor. We followed those studies with direct immunization of tumor-bearing mice with murine brain tumorderived chaperones that resulted in tumor antigen-specific responses and significantly reduced tumor burden. Thus, brain tumor HSPs may play a cytoprotective role for cells, but HSP expression, localization, and "exogenous" immunization may also be a means of immune notification, possibly leading to new therapeutic strategies against these highly refractory and almost uniformly lethal tumors.

\section{Materials and Methods}

Cell lines and culture. The brain tumor cell lines D56MG (an adult glioma line) (Preissig et al., 1979; Bullard et al., 1981), D392MG (adult glioma) (Ostrowski et al., 1991), D341MED (medulloblastoma) (Friedman et al., 1988), and SMA560 (a murine anaplastic astrocytoma) (Serano et al., 1980; Sampson et al., 1997) were grown in Improved MEM zinc option media supplemented with heat-inactivated fetal calf serum to $10 \%$ (Invitrogen, Carlsbad, CA). Adherent cells in log phase of growth were harvested, and their viability was determined by trypan blue exclusion.

Heat shock experiments. For induction of heat shock expression in cell lines, the media from the cells were carefully removed (or harvested from pelleted cells for the nonadherent lines). Cells were rinsed gently with sterile PBS and then overlaid with prewarmed $\left(42^{\circ} \mathrm{C}\right)$ media; dishes were placed in a $42^{\circ} \mathrm{C}$ incubator for $1 \mathrm{~h}$. After heat shock, the media were removed and replaced with $37^{\circ} \mathrm{C}$ media. Cells were allowed to recover from that point on for periods of $2,4,8$, or $24 \mathrm{~h}$ (as indicated in the text, figures, and/or figure legends) before harvesting for preparation of lysates. For fluorescence-activated cell sorting (FACS) experiments and media ELISA analyses, cells and media were collected after $24 \mathrm{~h}$ after the end of heat shock.

Cell lysate preparation and Western blotting. Cell lysates from the untreated and heat-shocked cells were prepared by sonicating cell pellets in $0.5 \mathrm{ml}$ of radioimmunoprecipitation assay (RIPA) buffer, followed by incubation at room temperature for $5 \mathrm{~min}$ and then harvesting lysate supernatants by centrifugation. Protein concentrations were determined using a Bradford assay with serum albumin as the standard. Twenty microgram samples were prepared in lithium dodecyl sulfate (LDS) sample buffer with 2-mercaptoethanol (Invitrogen) and electrophoresed on a $4-12 \%$ gradient bis-Tris gel (Invitrogen). The proteins were then electrotransferred to nitrocellulose membranes using $1 \times 3-(N-$ morpholino)-propanesulfonic acid/20\% methanol transfer buffer (Invitrogen) in an XCell II Blot Module (Invitrogen). Membranes were blocked by incubation in 3\% milk/PBS plus $0.5 \%$ Tween 20 (PBST) overnight at $4^{\circ} \mathrm{C}$. The blots were then probed with the following antibodies at a 1:1000 dilution in 1\% milk/PBST (all from Nventa Biopharmaceuticals, San Diego, CA): anti-HSP70 (catalog \#SPA-810), anti-HSP27 (SPA-803), anti-HSP25 antibody (against murine HSP25/27; SPA-801), anti-HSC70 (SPA-815), anti-GRP 75 (SPA-825), anti-GRP 78 (SPA826), and anti-HSP90 (SPA-830). Another anti-HSP27 antibody (vs murine HSP25/27) was from R\&D Systems (Minneapolis, MN) (antibody AF1580). The anti-HspBP1 antibody (a kind gift from Dr. Vince Guerriero, University of Arizona, Tucson, AZ) (Papp et al., 2005), was applied at $1 \mu \mathrm{g} / \mathrm{ml}$. After $1 \mathrm{~h}$ incubation at room temperature, the blots were washed with PBST. Blots were incubated with species-appropriate secondary antibodies (donkey anti-rabbit IgG, goat anti-rat IgG, sheep antimouse IgG, and donkey anti-sheep/goat; all from GE Healthcare, Little Chalfont, UK) used at 1:5000 dilutions for $1 \mathrm{~h}$. Secondary antibodies used were directly conjugated with horseradish peroxidase (HRP), with the exception of the donkey anti-sheep/anti-goat-biotin conjugate. After secondary antibody incubations, membranes received three consecutive 30 min washes in PBST and two 10 min washes in $\mathrm{dH}_{2} \mathrm{O}$; the membranes were incubated in enhanced chemiluminescent (ECL) substrate [Pierce (Rockford, IL) SuperSignal West Pico] for 5 min, exposed to Kodak (Rochester, NY) BioMax autoradiography film, and developed. For blots probed with anti-HspBP1, which used the biotinylated donkey antisheep/anti-goat IgG secondary antibody, a tertiary reagent of streptavidin HRP (Zymed Laboratories, South San Francisco, CA) (30 min at a 1:5000 dilution) was required before ECL development. Blots were reprobed with an anti-actin antibody (Sigma-Aldrich, St. Louis, MO) followed by secondary antibodies and development as described. Bands were quantified relative to actin using NIH Image.

Tumor tissue analyses. Xenograft tumors or the syngeneic SMA560 tumor were grown in $\mathrm{BALB} / \mathrm{c} n u / n u$ mice or $\mathrm{VM} / \mathrm{Dk}$ mice, respectively. Tumors were aseptically harvested from killed animals and were flashfrozen for later biochemical analyses (Western blotting) or were fixed in $10 \%$ formaldehyde for paraffin embedding and sectioning for IHC. For Western blotting, tumors were homogenized and prepared for LDSPAGE and electrotransfer, as described above. Western blots of tumor lysates were probed with the same antibodies as those used for the cell line studies [SPA-801 (anti-HSP25; Nventa Biopharmaceuticals) was used on tumor blots for SMA560]. For IHC, briefly, 5- $\mu \mathrm{m}$-thick sections of formalin-fixed, paraffin-embedded tumor or murine brain were placed on positively charged slides. The slides were deparaffinized, and antigen retrieval was performed by microwave heating in $10 \mathrm{~mm}$ citrate buffer, pH 6.0 (Zymed Laboratories), or with proteinase K treatment (Dako North America, Carpinteria, CA), followed by treatment with $0.3 \%$ $\mathrm{H}_{2} \mathrm{O}_{2}$ in methanol. After blocking in serum matched to the secondary antibodies for $1 \mathrm{~h}$, the sections were incubated with primary antibodies at $4^{\circ} \mathrm{C}$ overnight. Slides were washed in PBS and incubated with biotinylated secondary antibodies at room temperature for $1 \mathrm{~h}$. This was followed by washing and addition of tertiary streptavidin HRP conjugate (Vectastain ABC kit; Vector Laboratories, Burlingame, CA) for $30 \mathrm{~min}$ at room temperature. Finally, slides were washed, and the immunostain was developed with DAB solution (Pierce) for 5 min. After counterstaining, the sections were mounted with coverslips for observation. The antibodies used were rabbit anti-HSP90 (used at $0.25 \mu \mathrm{g} / \mathrm{ml}$; catalog \#4874; Cell Signaling Technology, Danvers, MA), rabbit anti-GRP78 (antiserum used at 1:10,000 dilution; SPA-826; Nventa Biopharmaceuticals), rabbit anti-GRP75 (used at $2 \mu \mathrm{g} / \mathrm{ml}$; catalog \#RB-10470; Lab Vision, Fremont, CA), rabbit anti-HSC70 (antiserum used at 1:10,000 dilution; SPA-816; Nventa Biopharmaceuticals), rabbit anti-HSP70 (used at $3 \mu \mathrm{g} /$ $\mathrm{ml}$; catalog \#4876; Cell Signaling Technology), sheep anti-HspBP1 (used at $2.5 \mu \mathrm{g} / \mathrm{ml}$; from Dr. Vince Guerriero), and rabbit anti-HSP27 (used at $3 \mu \mathrm{g} / \mathrm{ml}$; catalog \#AF1580; R\&D Systems). Normal sheep, normal rabbit $\mathrm{IgG}$, and normal rabbit serum (Sigma-Aldrich) were used as negative controls at the same concentration or dilution as the primary antibodies. Secondary antibodies were a biotinylated goat anti-rabbit IgG used at 1:200 dilution (catalog \#65-614; Zymed Laboratories) and a mouse monoclonal anti-goat/anti-sheep biotinylated antibody (clone GT-34; Sigma) used at 1:500 dilution.

Fluorescence-activated cell sorting. Flow cytometric analyses were performed on cells before and after heat shock. Cells were harvested, washed, fixed with $4 \%$ paraformaldehyde, and washed again. For direct FACS, cells were incubated with FITC-labeled antibodies at $10 \mu \mathrm{g} / \mathrm{ml}$ for $60 \mathrm{~min}$ rotating at $4^{\circ} \mathrm{C}$ in the dark, washed, and then acquired and analyzed on a FACSCalibur using CellQuest software (BD Biosciences Immunocytometry Systems, San Jose, CA). For indirect FACS, primary antibodies were used as above, washed, and then incubated with species- and isotypeappropriate fluorescein-labeled secondary antibodies (Sigma-Aldrich). In all cases, species or isotype control antibodies were used to determine background. Antibodies directed against the human chaperones used in 
FACS included anti-human Hsp27-FITC (clone G3.1; SPA-800FIF; Nventa Biopharmaceuticals), anti-Hsp70-FITC (clone C92F3A-5; SPA810FIF), anti-HSP60 (SPA-805), anti-HSC70 [rat monoclonal antibody (mAb) clone 1B5; SPA-815], anti-HSP90 (SPA-830), anti- $\alpha$ B-crystallin (clone 1B6.1-3G4; SPA-222), anti-calreticulin (clone FMC75; SPA-601), anti-GRP94 (rat mAb clone 9G10; SPA-850), anti-BiP/GRP78, antiHSP75/TRAP1, and anti-HSP110 (clones 40, 42, and 21, respectively; BD Biosciences Transduction Laboratories, Lexington, KY), anti-HspBP1 (mAb 10201; Orbigen, San Diego, CA), and anti-GPR170/ORP150 (clone 2F07; Immuno-Biological Laboratories, Gunma, Japan) (for results of additional FACS analyses with these antibodies, see supplemental Table 1, available at www.jneurosci.org as supplemental material). Purified $\mathrm{mAbs}$ were labeled as necessary using sulfobiotin- $N$ hydroxysuccinimide ester (NHS)-fluorescein (Pierce), and the unreacted fluor was removed by dialysis with PBS. Antibodies were used in these assays at $10 \mu \mathrm{g} / \mathrm{ml}$.

Quantitative FACS. Quantitative FACS (QFACS) analyses were performed in which murine monoclonal antibodies for particular chaperone/cochaperone antigens were available. QFACS protocols for determination of cell surface antigen density were described previously (Wikstrand et al., 1997; Kuan et al., 2000) using Quantum Simply Cellular $\mathrm{ABC}$ microspheres (Bangs Laboratories, Fishers, IN). Briefly, the beads consist of four populations of calibrated antigen-binding capacity (coated with goat anti-mouse Fc-specific antibody) as well as a fifth blank (nonbinding) population. When incubated with an excess of either specific or isotype-matched control $\mathrm{mAb}$-fluorescein, median fluorescence intensity was used to extrapolate surface receptor density (assumes a 1:1 antibody:antigen ratio) using QuickCal (Bangs Laboratories). Numbers reported refer to "receptor number" per cell, assuming a 1:1 antibody: antigen ratio.

ELISA for HSP27 and HSP70 in culture media. Cells in culture were either left at normal temperatures or heat shocked as described above. After exchanging the media after heat shock, cells were allowed to recover for $24 \mathrm{~h}$, and the media were harvested for ELISA analyses for the presence of HSPs 27 and 70 using kits from Nventa Biopharmaceuticals per the manufacturer's directions. To rule out the possibility that increases in HSPs in the media were released by dead or dying cells, viability was assessed from both cell populations before and after heat shock by trypan blue exclusion. There were no significant differences in the number of viable cells between the pre-heat shock and post-heat shock groups, and there were no differences compared with control cell populations.

Cell surface biotinylation. Cells were grown to $80 \%$ confluency, washed, and labeled with a membrane-impermeant biotinylation reagent (EZ-Link Sulfo-NHS-LC Biotin; Pierce) according to the manufacturer's instructions. Cells were lysed in RIPA buffer as described above, and the biotinylated (membrane) proteins were precipitated from the lysate by incubation with NeutrAvidin beads (Pierce). The beads were washed extensively in RIPA buffer, and biotinylated proteins were eluted in LDS sample buffer. The protein samples were checked for cytosolic contaminants by Western blotting. Probes for cytosolic proteins included anti-actin, anti-tubulin, and anti-GAPDH (glyceraldehyde-3 phosphate dehydrogenase) antibodies (all from Sigma). All biotinylated samples were free of cytosolic proteins. Blots of biotinylated membrane proteins were probed with HSP antibodies as described above.

Exosome preparation and analyses. Exosomes were prepared from the media of cell lines by modifications of methods described previously (Escola et al., 1998; Chen et al., 2006). Briefly, spent media were collected from $4-8 \times 10^{7} \mathrm{D} 54 \mathrm{MG}$ or SMA560 tumor cells after $48 \mathrm{~h}$ in "exosomefree" media (i.e., that which had been previously centrifuged overnight at $100,000 \times g$ to remove endogenous exosomes from fetal calf serum). The harvested culture supernatant was subjected to differential centrifugation, beginning with centrifugation at $800 \times g$ for $10 \mathrm{~min}$ at $4^{\circ} \mathrm{C}$. The supernatant was then centrifuged at $10,000 \times g$ for $10 \mathrm{~min}$ at $4^{\circ} \mathrm{C}$, and that supernatant was centrifuged at $100,000 \times g$ at $4^{\circ} \mathrm{C}$ for $3 \mathrm{~h}$. The resulting exosome pellet was resuspended in a large amount of PBS and again centrifuged at $100,000 \times g$ for $60 \mathrm{~min}$ at $4^{\circ} \mathrm{C}$. The pellet was resuspended in $0.2 \mathrm{ml}$ of PBS and was analyzed by electron microscopy and biochemically by LDS-PAGE and Western blotting. Probes for Western blots consisted of antibodies against HSP90 (catalog \#4874; Cell Signal- ing Technology), HSP/HSC70 (SPA-820; Nventa Biopharmaceuticals), HSP60 (SPA-805), and HSP27 (SPA-803) or murine HSP25 [SPA-801 and AF1580 (R\&D Systems)]. Exosomes were solubilized in RIPA buffer, and total protein was quantified with the BCA protein assay (Pierce) using BSA as a standard. Exosome preparations were analyzed by electron microscopy after incubation on formar-coated grids, negative staining with uranyl acetate, and observation with a Philips transmission electron microscope (Philips, Best, The Netherlands) operated at $80 \mathrm{kV}$.

In vivo tumor growth assays. All animal experimentation was done under approval of Duke University Institutional Animal Care and Use Committee protocol management. The murine anaplastic astrocytoma line SMA560 was used to determine whether heat shock affected tumor growth, perhaps through immune system involvement. This tumor line is syngeneic to the VM/Dk strain of mice raised in-house at the Cancer Center Isolation Facility at Duke University. This murine brain tumor model has been described previously (Serano et al., 1980; Sampson et al., 1997). For these experiments, SMA560 cells were heat shocked as described above, allowed to recover for $24 \mathrm{~h}$, harvested from plates, and washed three times in PBS, and 100,000 cells in $0.2 \mathrm{ml}$ of PBS were injected subcutaneously into female VM/Dk mouse flanks. Control (non-heat stressed) SMA560 cells experienced the same media exchange, harvest conditions, and inoculation procedures. Tumor growth was monitored over time using calipers to measure diameters in length (defined as the longer axis) and width (defined as the shorter axis). Tumor volumes were computed using the formula length $\times$ width $^{2} \times(\pi / 6)$. The experiments were repeated using immune-incompetent $n u / n u$ $(\mathrm{BALB} / \mathrm{c})$ mice, in which both sets of tumors grew at equal rates. For syngeneic VM/Dk mice that survived their initial tumor challenge (i.e., those receiving heat-treated tumor cells), those mice were rechallenged $90 \mathrm{~d}$ after their first tumor inoculation on the flank opposite from the first implantation. Mice received 100,000 non-heat stressed SMA560 cells; tumor volumes were measured and compared with the growth rates of the same number of tumor cells injected into age-matched, naive VM/Dk mice. Growth rates were statistically indistinguishable.

\section{Chaperone-rich cell lysate preparations}

Chaperone-rich cell lysate (CRCL) was prepared from in vivo-grown SMA560 tumors by methods described by Graner et al. $(2000,2003)$ and Kislin et al. (2007) using a free-solution-isoelectric-focusing technique (FS-IEF). Briefly, tumor tissues were homogenized in detergentcontaining buffers, and high-speed supernatants were obtained. The dialyzed supernatants were mixed with detergents and conjugate acid-base pairs (for $\mathrm{pH}$ gradient establishment), and the solution was made to $6 \mathrm{M}$ urea. The mixture was subjected to FS-IEF in a Rotofor device (Bio-Rad Laboratories, Hercules, CA) at 15W constant power, and fractions were harvested and analyzed for chaperone content. Fractions of interest (those containing glucose-regulated protein 94, HSP90, HSP70, and calreticulin) were pooled and prepared as vaccines by dialysis, detergent removal, and centrifugal concentration. Vaccines were tested for endotoxin with the Limulus Amebocyte Lysate assay (Lonza Walkersville, Walkersville, MD) and were found to contain $<0.01$ endotoxin units $/ \mu \mathrm{g}$ protein. Vaccines were diluted in PBS and stored in $200 \mu \mathrm{g}$ aliquots at $-70^{\circ} \mathrm{C}$ until used.

\section{CRCL vaccinations for enzyme-linked immunospots}

$\mathrm{VM} / \mathrm{Dk}$ mice (three per group) were each immunized subcutaneously with $20 \mu \mathrm{g}$ of SMA560-derived CRCL on day -14 and again on day -7 . Spleens were harvested for enzyme-linked immunospot (ELISPOT) assays (described below) on day 0 .

\section{ELISPOT}

ELISPOT assays were performed to assess interferon- $\gamma$ production of splenocytes from vaccinated mice after in vitro stimulation with CRCL or peptides as described by Graner et al. (2003). Splenocytes $\left(10^{6} / \mathrm{ml}\right)$ were cultured with $5 \mu \mathrm{g} / \mathrm{ml}$ SMA560-derived CRCL or $5 \mu \mathrm{g} / \mathrm{ml}$ glycoprotein nonmetastatic B extracellular domain (GPNMBecd) or GPNMB peptides for $48 \mathrm{~h}$ on ELISPOT plates from kits from R\&D Systems and ELISPOT plates probed and developed according to manufacturer's protocol. Spots were counted with the aid of a dissecting microscope. GPNMBecd was prepared as described by Kuan et al. (2006); GPNMB 
A

D54MG

Recovery time following heat shock

HSP90

$\begin{array}{lllll}0 & 2 & 4 & 8 & 24 \\ \mathrm{hr}\end{array}$

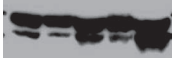

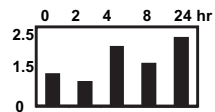

GRP78

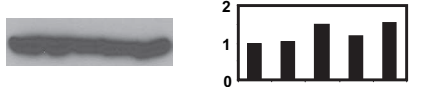

GRP75
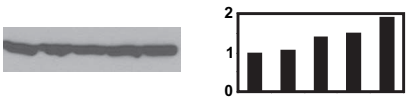

HSC70

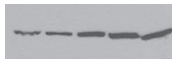

HSP70

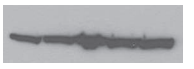

HSP27

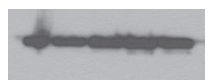

HspBP1

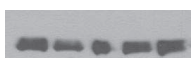

Actin

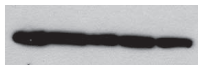

Western Blot

Fold Increase Over "0" Time Point Normalized to Actin (note Y-axes scales)

C

D341MED

Recovery time following heat shock

$\begin{array}{lllll}0 & 2 & 4 & 8 & 24 \\ \mathrm{hr}\end{array}$

HSP90

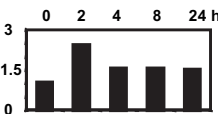

GRP78

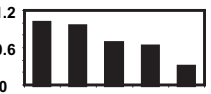

GRP75

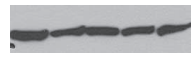

HSC70

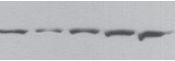
0.8
0 $\int_{0}^{3.5} \square$

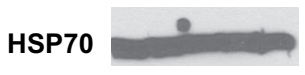
$\sqrt[2.5]{1.5}$

HSP27

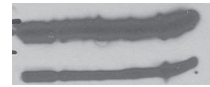

HspBP1

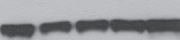
\begin{tabular}{l|l|l|l|l|l|}
1.8 \\
0.6 \\
0
\end{tabular} 1.6
0.8

Actin

Western Blot

Fold Increase Over "0" Time Point Normalized to Actin (note Y-axes scales)

\section{B D392MG}

Recovery time following heat shock
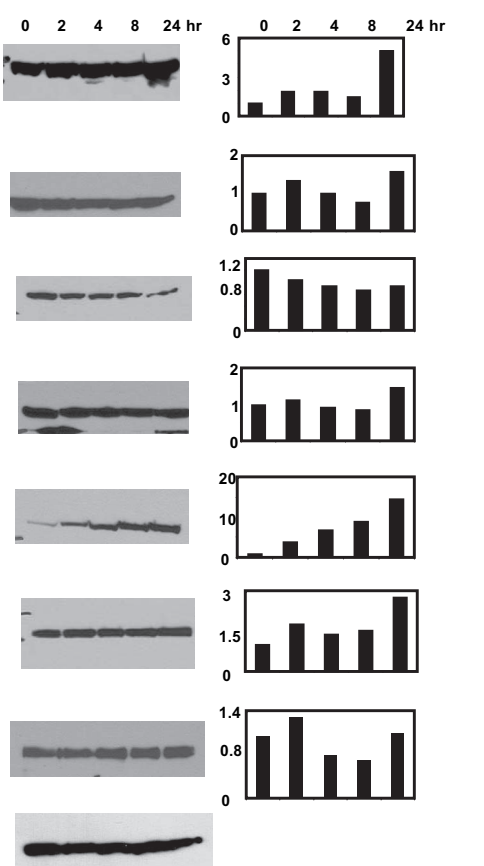

Western Blot

Fold Increase Over "0" Time Point Normalized to Actin (note Y-axes scales)

\section{SMA560}

Recovery time following heat shock $\begin{array}{lllll}0 & 2 & 4 & 8 & 24 \\ \mathrm{hr}\end{array}$
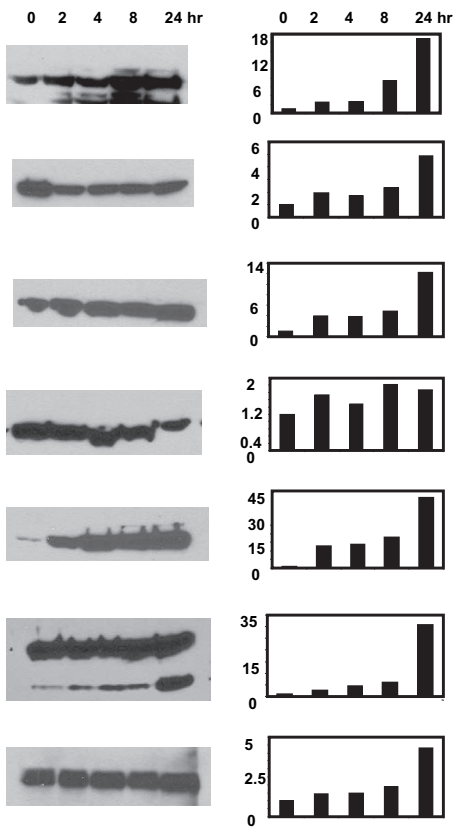

Western Blot peptide A is PSAYMREHNQLNGWSSDEc (singleletter amino acid designation; amino acids $34-51$ with a C-terminal cysteine added for production purposes). GPNMB peptide B is PGPCPPPPPPPRPSKPTPSLGP (amino acids 320-341). Both peptides were prepared by AnaSpec (San Jose, CA).

CRCL vaccinations of tumor-bearing mice

$\mathrm{VM} / \mathrm{Dk}$ mice (6- to 8-week-old females; 10 mice per group) were inoculated subcutaneously with 100,000 SMA560 tumor cells; $5 \mathrm{~d}$ later, mice received subcutaneous injections of PBS vehicle or $50 \mu \mathrm{g}$ of SMA560derived CRCL vaccines on the flank opposite from their tumor injections. Tumor volumes were measured two to three times per week with calipers, and tumor volumes were calculated using the formula (length) $\times$ $\left(\right.$ width $\left.^{2}\right) \times(\pi / 6)$.

Statistics. Where meaningful, Student's $t$ test was used to determine statistical significance. All experiments were repeated at least twice and, in some cases, up to five times.

\section{Results}

Chaperone protein expression after heat shock of brain tumor cell lines

Initial characterization of chaperone protein expression in selected brain tumor cell lines was done by Western blotting of the tissue culture lines before and after nonlethal heat shock. Although we have examined HSP/chaperone protein "outputs" in numerous brain tumor cell lines and xenografts (see supplemental Table 1, available at www.jneurosci.org as supplemental material), these particular cell lines were chosen as representatives of various categories: a line derived from a high-grade adult glioma that is well characterized and described in the literature (D54MG); another high-grade adult gliomaderived line that is less well characterized (D392MG); a line derived from a medulloblastoma from a pediatric patient (D341MED); and a syngeneic murine glioma suitable for immune studies (SMA560). Cells were heat shocked at $42^{\circ} \mathrm{C}$ for $1 \mathrm{~h}$ followed by recovery of periods from 2 to $24 \mathrm{~h}$. Cells were harvested at 2, 4, 8, and $24 \mathrm{~h}$ after the termination of heat shock, and control cells (cells kept at $37^{\circ} \mathrm{C}$ ) were harvested and referred to as the " 0 " time point. Lysates were prepared from equal numbers of cells at each time point (viabilities after heat shock remained $\pm 10 \%$ of control cells). Proteins were electrophoresed and electroblotted, and blots were probed with

\section{$\leftarrow$}

Figure 1. Heat shock generally increases chaperone/heat shock protein expression in brain tumor cell lines. $\boldsymbol{A}-\boldsymbol{D}$, Cell lines derived from patient GBMs (D54MG, $\boldsymbol{A}$; D392MG, $\boldsymbol{B}$ ), from a medulloblastoma (D341MED, $C$ ), or from a murine astrocytoma $(S M A 560, D)$ were subjected to sublethal heat shock $\left(42^{\circ} \mathrm{C}, 1 \mathrm{~h}\right)$ and allowed to recover for the time periods indicated after heat shock (2-24 h). Lysates were prepared from cells at the time points indicated (" 0 " refers to before heat shock); proteins were separated by LDS-PAGE and Western blotted. Antibody probes are listed on the left. Quantitative comparisons (bar graphs) were made by densitometry relative to actin staining (average of two independent experiments). Error bars indicate SD. All other SDs were $<10 \%$. Cells were $>95 \%$ viable whether heat shocked or not. 
antibodies to various chaperone/heat shock proteins, with actin antibodies as loading controls. The chaperone repertoire analyzed included the more highly stress-inducible members (HSPs 27, 70, and 90) as well as additional members of the HSP70 family: heat shock cognate 70 $\mathrm{kDa}$ (HSC70, the constitutively expressed cytosolic HSP70), glucose-regulated protein $78 \mathrm{kDa}$ (GRP78, the HSP70 of the endoplasmic reticulum), and GRP75, also called mortalin (Wadhwa et al., 1993, 2002), the mitochondrial HSP70. We also probed for an HSP70 family cochaperone, the nucleotide exchange factor heat shock protein-binding protein 1 (HspBP1) (Raynes and Guerriero, 1998).

Figure 1 shows the Western blot results for the various lysates over the time courses along with quantifications from densitometric scans of the blots. The values are based on the density comparisons of the blot for a given time point for the chaperone/HSP to actin. The ratio of HSP to actin for the 0 time point was defined as 1 , and all other outputs are shown as fold changes over that ratio. Based on that readout, there is no consistent trend to HSP expression after heat shock that applies to all of the cell lines. D54MG shows a mild heat response over time across all of the chaperones/HSPs examined (Fig. 1A), as does D341MED (Fig. 1C). However, both of those lines also demonstrate relatively high levels of HSPs 90 and 27, and the inducible HSP70, under normal conditions ( 0 time point), as if these stress protein expressions are uncoupled from stress induction. The graphical trend (i.e., expression kinetics) for D54MG shows an increase in HSP expression $>24 \mathrm{~h}$, whereas the peak for most of the D341MED HSPs is earlier. D392MG (Fig. $1 B$ ) and especially SMA560 (Fig. $1 D$ ) both show more robust heat shock responses, as gauged by HSP 90 and inducible HSP70 expression, whereas SMA560 also shows potent HSP27 induction. It should be noted that the anti-HSP27 antibody used here has questionable reactivity against murine HSP25 (Graner, unpublished observations); however, we found that antibody to react well in Western blots from cell lysates (as in Fig. $1 D$ ), as well as in flow cytometry (see below) (see Fig. 3) with the murine SMA560 cells/cell lysates. However, mAb did not react with tumor-derived murine HSP25/27 from SMA560 in vivogrown tumor lysates (see below) (Fig. $2 \mathrm{~A}$ ), nor did it react with exosome proteins from SMA560 tissue culture cells (see below) (see Fig. 6). In both of those cases, another antibody relatively specific for murine HSP25 was used successfully for Western blotting, although it did show unusual reactivity with SMA560 exosome proteins. This may be because of differential posttranslational modifications or HSP25/27 variants, depending on the source and localization of the small HSP. In addition, D341MED and SMA560 also show an additional lower-molecular-weight band reactive with the HSP27 antibody. This additional band was not included in the quantification, and its nature is unclear. It is possibly a modified or breakdown product of HSP27 or a closely related member of the small HSP family (such as HSP22).

There may be some correlation between increased expression
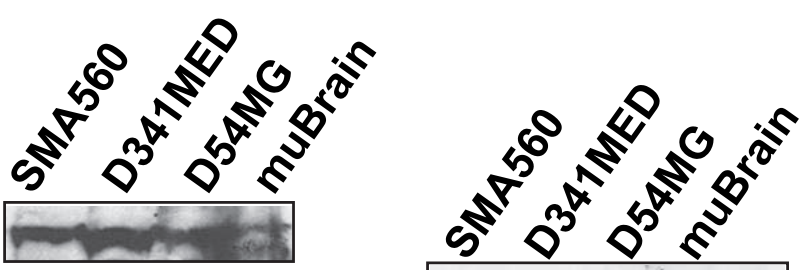

250kDa

150

100

75

50

37

25

20

Figure 2. Heat shock and chaperone/cochaperone proteins are highly expressed by brain tumor xenografts or syngeneic tumors grown in vivo compared with normal brain. Western blots of tumor or brain lysates were probed with the antibodies listed is broken into three parts to indicate that the murine tissues (SMA560 and brain) were probed with different HSP27 antibodies than were the human xenograft tumors (D54MG and D341MED).

of the HSP/HSC70 cochaperone HspBP1 and increased expression of HSP or HSC70 in D341MED and SMA560 cells (Fig. $1 C, D)$, but the changes in HspBP1 expression are not dramatic. Although tumors do tend to overexpress HspBP1 compared with their normal tissue counterparts (Raynes et al., 2003), HspBP1 expression is not coordinately regulated in proportion to HSP70 expression changes (Gottwald et al., 2006).

A likely explanation for at least some of the numerical changes in HSP measurements is because of the reduced amounts of actin found in the heat-shocked cells over time, because the values are normalized to actin. Most cells respond to heat shock by upregulating the expression of stress-inducible proteins while concurrently downregulating expression of most other polypeptides (Tanguay, 1983; Craig, 1985; Burdon, 1987; Welch, 1987). Thus, whereas the total protein loads for each lane were the same, the amount of actin in those samples is likely to decrease as a steadystate measure until the cell fully recovers from the stress. The kinetics of that recovery may vary; for instance, D341MED shows an early peak in HSP expression compared with the other lines, and its actin production is returned to normal by $24 \mathrm{~h}$ (Fig. 1C).

\section{Chaperone/heat shock protein expression in human brain} tumor xenografts and syngeneic murine brain tumors

To verify that chaperone/HSP expression is maintained in vivo in these brain tumor cells (i.e., to demonstrate that such expression is not a cell culture artifact), lysates were prepared from xenograft tumors D54MG and D341MED (D392MG has not been successfully grown as a transplantable xenograft model). Lysates were also prepared from SMA560 tumors grown in syngeneic VM/Dk 


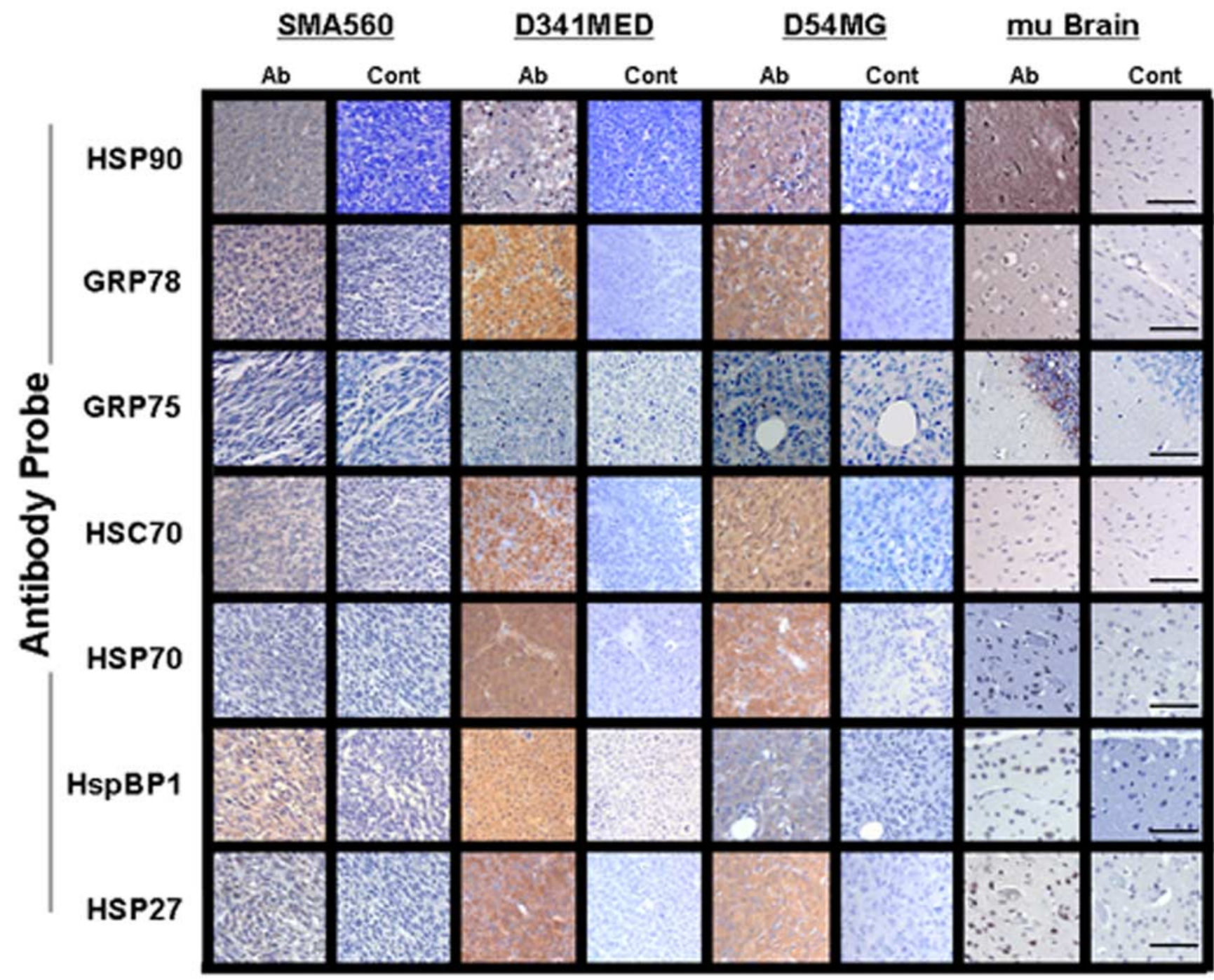

Figure 3. Brain tumors express high chaperone levels as seen in IHC. IHC of in vivo-grown brain tumors and normal mouse brain was performed on formalin-fixed, paraffin-embedded sections with the antibodies listed on the left (staining shown in Ab columns) or with control (Cont) antibodies. "mu Brain" indicates sections from nu/nu mouse brain cortex. Scale bars, $100 \mu \mathrm{m}$.

mice, and whole rodent brain was used as a normal control tissue. Lysate proteins were separated by SDS-PAGE and electrotransferred for Western blotting, as described above. Blots were probed with antibodies to HSPs 90, 70, and 27, to HSC70, to GRPs 78 and 75, to the cochaperone HspBP1, and to actin. Like most normal tissues, brain expresses the constitutive chaperones such as HSP90, GRPs 78 and 75, and HSC70, but it expresses relatively little of the more highly inducible HSP70, HSP27, and the cochaperone HspBP1. The in vivo-grown tumors, however, express each of the chaperones/cochaperones at high levels, as well as more of the highly inducible HSPs 27 and 70 (Fig. 2). The metabolic stresses tumors face while growing as tissues may account for their relatively high HSP expression levels (Graner and Bigner, 2006).

These results are confirmed by IHC (Fig. 3) on paraffin sections of in vivo-grown tumors and rodent brain using antibodies to HSP27, HSP70, HSC70, GRP75, GRP78, HSP90, and HspBP1. From the IHC, the distribution of chaperones and HSPs can be seen, as well the intensities of staining. Normal mouse brain, known to express relatively high amounts of HSP90, GRP78, and GRP75 (Fig. 2) displays similar strong reactivity in IHC, although regionally or cell-specifically localized. HSP90 is expressed in most all neurons in rodent brain (Itoh et al., 1993; Gass et al., 1994), and Figure 3 displays cerebral cortex staining, with glia remaining unstained. GRP78 is shown here in the molecular layer of the cerebral cortex, as demonstrated previously (Chen et al., 2000). GRP75 was expressed strongly in the granular layer of the hippocampus in patterns reminiscent of those seen previously (Kaul et al., 1997). The brain tumor cell lines that also grow in vivo (D54MG, D341MED, and SMA560) also show strong staining in IHC with most all of the antibodies. Curiously, nuclear staining of HSPs is relatively rare in these sections, despite the intensities, which may have relevance for the stress response (Langer et al., 2003). The endoplasmic reticulum chaperone GRP78 is also present in all of the tissues examined but with particularly strong, uniform staining in the human tumors. Much of the staining appears diffuse and cytoplasmic, with no vivid reticular structures evident. The murine astrocytoma SMA560 is more heterogeneous with regard to intratumoral distribution of staining and has a more reticular pattern in cells that stain positively for GRP78. Like GRP78, the constitutive HSC70 (HSP73) is expressed by all of the tissues examined but is very strongly and uniformly expressed by the human tumor xenografts, weaker and less uniformly in the murine tumor, and rela- 
tively weakly in the rodent brain, shown here staining pyramidal and nonpyramidal neurons of the cerebral cortex. This localized pattern of staining in brain is similar to that for the stress-inducible HSP70 (Manzerra and Brown, 1996) and its cochaperone HspBP1, in which pyramidal neurons of the cerebral cortex show dark cytoplasmic staining (to the best of our knowledge, this is the first use of the HspBP1 antibody for IHC). This is also similar to HSP27 staining of the rodent brain, although that staining is more diffuse throughout the cortex. Previous reports of HSP27 staining in nonstressed rodent brain indicate low expression of the HSP (Kato et al., 1995), whereas other publications show strong brainstem and sensory and motor neurons (Plumier et al., 1997), although the use of different antibodies and different sections for IHC may explain some of these discrepancies. Again, nuclei were largely spared, indicative of a lack of significant stress-induced translocation of the chaperone into cell nuclei.

\section{Heat shock proteins are present on the} cell surface of human and murine brain tumor cell lines

There has been increasing interest in the localization and potential biological significance of chaperone/heat shock proteins and other chaperones on tumor cell surfaces (Multhoff and Hightower, 1996; Graner and Bigner, 2005, 2006). HSP70 on tumor cells is immunologically relevant as a target for natural killer (NK) cells (Multhoff, 2002) and $\gamma \delta$ T-cells (Harada et al., 1998; Zhang et al., 2005), whereas cell membrane HSP27 is associated with a more aggressive phenotype in at least one murine model (Bausero et al., 2004). There has been recent interest in targeting cell surface GRP78 by a variety of peptidebased strategies (Arap et al., 2004; Davidson et al., 2005). We used flow cytometry and a QFACS analysis (see Materials and Methods) to examine the presence and extent of HSPs on the cell surfaces of D54MG, D392MG, D341MED, and SMA560. Figure 4 shows representative FACS profiles for D54MG, D341MED, D392MG, and SMA560 stained with directly fluoresceinated antibodies against HSPs 27 and 70, GRP78, and the cochaperone HspBP1. Table 1 presents the numbers of surface chaperones/ cochaperones per tumor cell (based on an assumed 1:1 antibody: antigen ratio). Assays were performed using cells that had been subjected to a $1 \mathrm{~h}$ heat shock at $42^{\circ} \mathrm{C}$ followed by a $24 \mathrm{~h}$ recovery, as well as with the same batch of cells cultured at normal temperatures. In almost every cell line, for every antibody/antigen complex measured, the chaperones/HSPs we examined were present on the surfaces of the cells at normal temperature, and those numbers tended to increase when cells were exposed to heat shock and allowed to recover. The fold increases ranged from $\sim 1.5$ - to $\sim 20$-fold after heat shock. Overall, the changes seen in indicated by gray fill. antibody:antigen ratio.
Antibody Probe

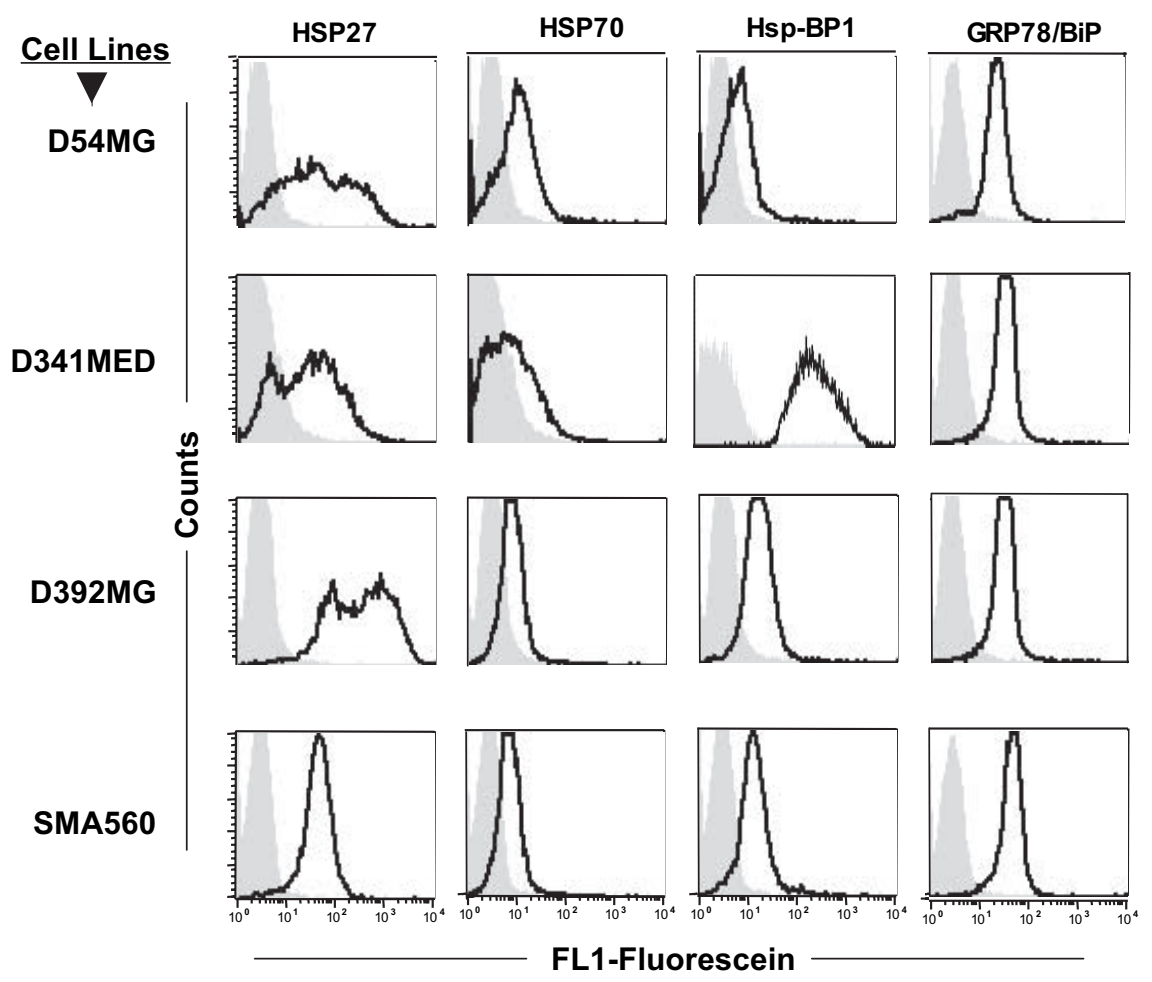

Figure 4. Flow cytometry of brain tumor cell surface HSPs 27,70, GRP78, and cochaperone HspBP1. Formalin-fixed cells were incubated with the antibodies listed (directly fluoresceinated) and were analyzed by FACS (dark tracing). The isotype control is

Table 1. Quantitative determinations of cell surface HSPs 27 and 70, GRP94, and HspBP1

\begin{tabular}{|c|c|c|c|c|c|}
\hline \multirow[b]{2}{*}{ Tumor } & \multirow[b]{2}{*}{ Cell target } & \multicolumn{4}{|c|}{ Antibody probe } \\
\hline & & HSP27 & HSP70 & GRP78/BiP & HspBP1 \\
\hline \multirow[t]{6}{*}{ Human } & D54MG & $3.8 \times 10^{4}$ & $1.9 \times 10^{4}$ & $4.2 \times 10^{4}$ & $3.1 \times 10^{4}$ \\
\hline & + Heat shock & $6.4 \times 10^{5}$ & $5.2 \times 10^{5}$ & $1.2 \times 10^{5}$ & $7.1 \times 10^{4}$ \\
\hline & D392MG & $1.1 \times 10^{6}$ & $2.5 \times 10^{5}$ & $2.1 \times 10^{5}$ & $7.6 \times 10^{4}$ \\
\hline & + Heat shock & $4.5 \times 10^{6}$ & $1.1 \times 10^{6}$ & $3.4 \times 10^{5}$ & $1.1 \times 10^{5}$ \\
\hline & D341MED & $1.9 \times 10^{5}$ & $4.5 \times 10^{4}$ & $8 \times 10^{4}$ & $3 \times 10^{4}$ \\
\hline & + Heat shock & $6.6 \times 10^{5}$ & $4.2 \times 10^{5}$ & $7.2 \times 10^{4}$ & $2.4 \times 10^{4}$ \\
\hline \multirow[t]{2}{*}{ Murine } & SMA560 & $8.2 \times 10^{3}$ & $<\mathrm{BKG}$ & $5.5 \times 10^{4}$ & $2.9 \times 10^{4}$ \\
\hline & + Heat shock & $1.1 \times 10^{4}$ & $1.2 \times 10^{5}$ & $6.5 \times 10^{4}$ & $2.8 \times 10^{4}$ \\
\hline
\end{tabular}

Brain tumor cell lines D54MG, D392MG, D342MED, and SMA560 were subjected to OFACS (see Materials and Methods) to determine the number of chaperone/cochaperone molecules on the tumor cell surfaces before and after heat shock. Numbers shown are calculated per cell, based on an assumed 1:1

total chaperone/HSP output measured in Western blot are reflected to some extent in the QFACS readouts, including the general lack of dynamic cell surface changes for GRP78 and HspBP1. Thus, after heat stress, there may be substantial redistributions of the HSP pools from within cells to the plasma membrane, but this is not a universal phenomenon for all of the stress proteins we examined. In addition, in our hands we saw little or no HSP90 on these cells by indirect or direct flow cytometry (R. I. Cumming, unpublished observations).

We verified the presence of various chaperones/HSPs as cell surface moieties by biotinylation of cell surface molecules using a membrane-impermeant biotinylation compound and enrichment of labeled proteins on avidin matrices. Select biotinylated proteins were identified by gel electrophoresis and Western blotting with specific antibodies. Western blots in Figure $5 A$ reveal the presence of HSP27, HspBP1, HSP70, and GRP78 on the surfaces of the D54MG, 
A

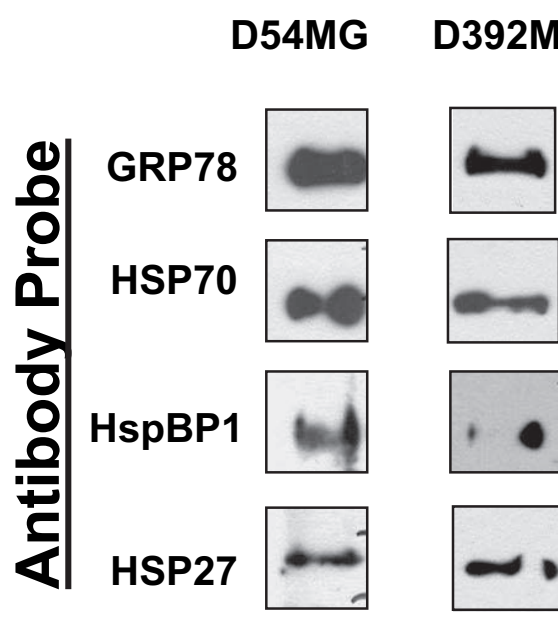

Cell Line

D341MED SMA560

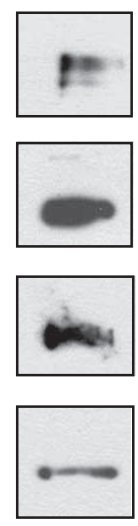

B

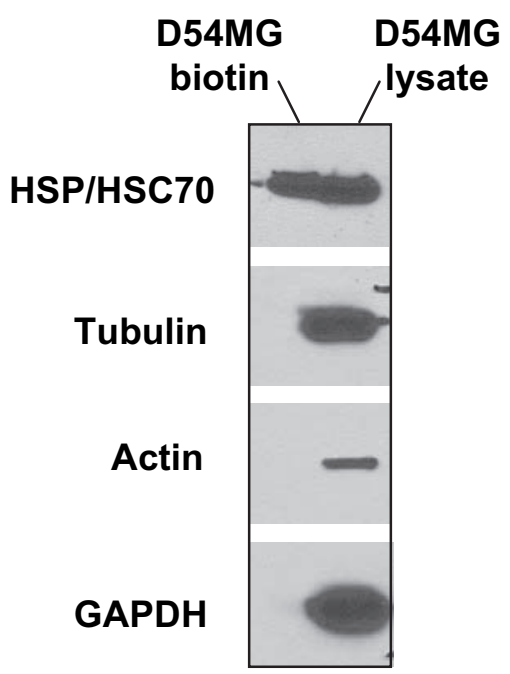

Figure 5. Cell surface biotinylation reveals that GRP78, HSPs 27 and 70, and HspBP1 are on the surfaces of brain tumor cell lines. $A$, Using membrane-impermeant biotin, the cell lines shown were surface biotinylated, and surface proteins were enriched on streptavidin matrices. Biotinylated proteins were separated on gels and Western blotted. Antibody probes are shown at left. $\boldsymbol{B}$, To verify that only surface proteins were labeled, the fractions unbound on the streptavidin beads (D54MG lysate) and the bound/eluted fractions (D54MG biotin) were probed with antibodies against cytosolic proteins tubulin, actin, and glyceraldehyde-3 phosphate dehydrogenase (GAPDH). HSP/HSC70 was found in both the nonbiotinylated cytosolic fraction and the labeled membrane fraction (as expected, from the results in $A$ ).

D392MG, D341MED, and SMA560 cell lines used in this study. The sole exception was that we were unable to detect biotinylated HSP25/27 from the murine SMA560 cell line despite numerous attempts and probing with several different HSP25/27 antibodies. It is conceivable that surface HSP25/27 in this mouse line does not biotinylate sufficiently for recovery; alternatively, the discrepancy between the FACS results and the surface biotinylation results may lie in an epitope configuration. The lack of cytoplasmic protein biotinylation is shown in Figure $5 B$. Thus, by both flow cytometry and cell surface biotinylation, chaperones, at least one cochaperone, and HSPs are present on the surfaces of brain tumor cell lines.

\section{Brain tumor cell lines release heat shock proteins and} exosomes into the extracellular space

Along with cell surface expression of chaperones/heat shock proteins, there are instances in which those (normally intracellular) proteins may be released into the extracellular milieu (Hightower and Guidon, 1989; Guzhova et al., 2001, 2001; Lancaster and Febbraio, 2005; Tytell, 2005; Evdonin et al., 2006; Mambula and Calderwood, 2006). For cells in tissue culture, HSPs may be measured in the conditioned media by Western blotting or ELISA. We examined the HSP output into spent media by D54MG, D392MG, D341MED, and SMA560 cells under normal and heat shock conditions. Figure $6 A$ shows that HSP27 is released in similar quantities from the human brain tumor lines examined under both normal conditions and after heat shock (nonetheless significantly different for D54MG and D392MG), whereas the murine line SMA560 appears to release no HSP27 (murine HSP25) as recognized by the antibody in the ELISA kit. However, HSP70 release by the cell lines is between 1.5 and 10 times higher after heat shock, with the largest release coming from the very heat-inducible SMA50 cell line (Fig. 6B). This release is not attributable to cell death, because the viable cell numbers (determined by trypan blue exclusion) were nearly identical both before and after heat shock (data not shown).

Another way in which heat shock proteins may enter the ex- tracellular environment is as components of exosomes, secreted membrane-delineated vesicles $(30-100 \mathrm{~nm}$ in diameter) that are usually thought to be of endosomal origin (derived from internal microvesicular bodies) (Chaput et al., 2004; Johnstone, 2006; Keller et al., 2006). These vesicles characteristically contain a number of HSPs, including HSPs 27, 60, 70, and 90 (Clayton et al., 2005). Exosomes have been isolated from the spent media of a number of cell lines (Keller et al., 2006) including cultured neurons (Faure et al., 2006). However, there appear to be no direct references in the literature to exosomes of brain tumor cell line origin. We obtained exosomes from the spent media of brain tumor lines D54MG and SMA560 by differential centrifugation. The electron micrograph shown in Figure $7 A$ depicts exosome preparations consisting of bilayered membranous vesicles with diameters between 50 and $100 \mathrm{~nm}$ and a typical exosome appearance. Western blot analyses of the exosome preparations showed a canonical content of HSPs 90, 70, 60 and 27 (Fig. 7B), although there is an unusual small HSP species found in the murine (SMA560) exosomes that may correspond to an uncharacterized mitochondrial sHSP (Downs et al., 1999; Dunlop and Muggli, 2000). In terms of total protein content, we were able to obtain $\sim 2 \mathrm{mg}$ of protein from $\sim 8 \times 10^{7}$ cells collected over a $48 \mathrm{~h}$ period ( $1.7 \pm 0.2 \mathrm{mg}$ for D54MG cells; $2.1 \pm 0.3 \mathrm{mg}$ for SMA560 cells). These amounts are at the high end of reported ranges (Hegmans et al., 2004; Mears et al., 2004; Chen et al., 2006), which may reflect the various methods of exosome isolation (and purity), as well as potential differences in exosome formation by different cell types. Thus, exosomes, along with a typical HSP cargo, are released from brain tumor cell lines. The function and biologic impact of these vesicles awaits additional study.

Heat stress abrogates SMA560 tumorigenicity in immune-competent animals

Because the murine anaplastic astrocytoma cell line SMA560 displayed prominent heat shock responses both intracellularly and extracellularly (Figs. 1D, 6B, Table 1), we hypothesized that this 

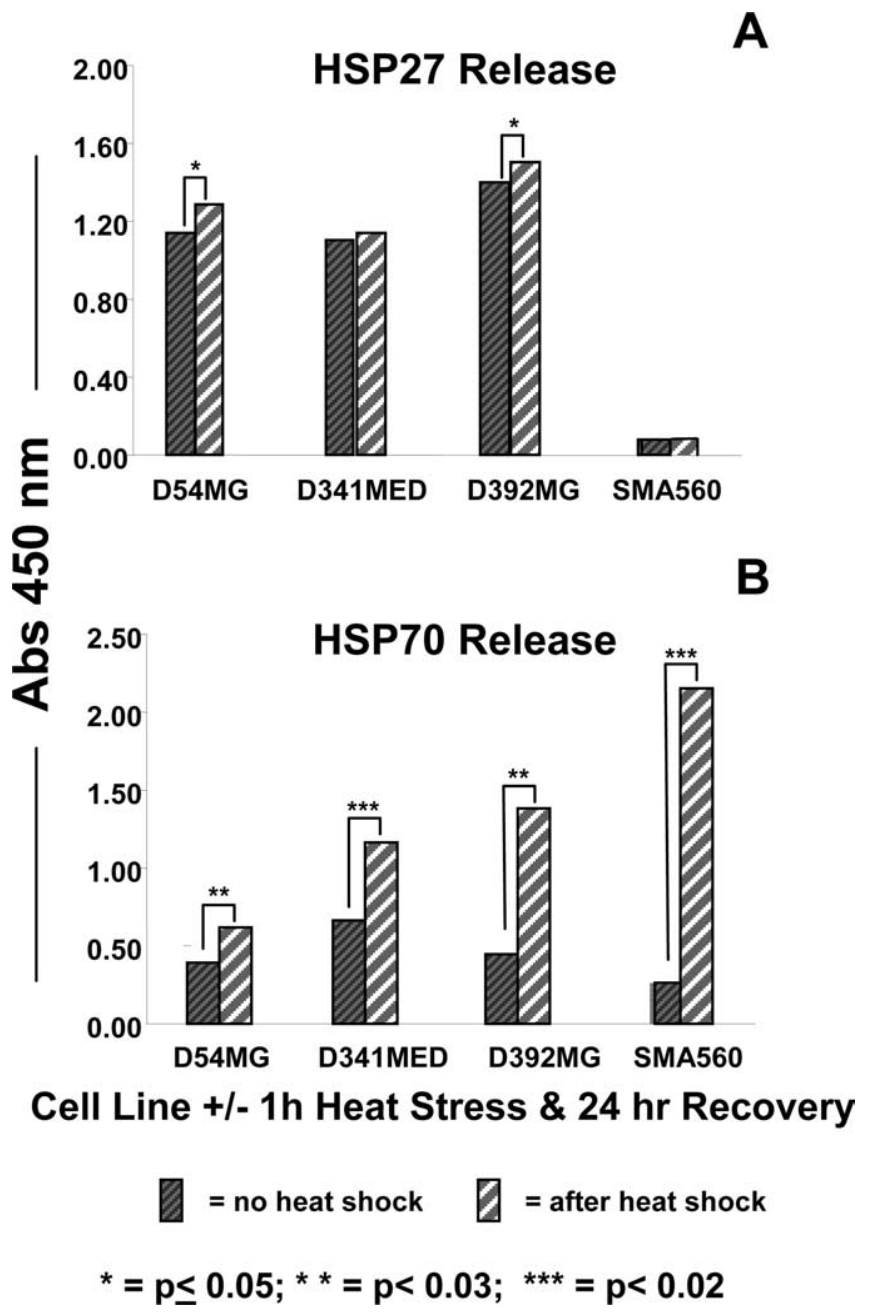

Figure 6. HSPs 27 and 70 are released into culture medium by brain tumor cell lines under normal and heat shock conditions. The cell lines listed were left untreated (dark hatched bars) or were heat stressed $\left(42^{\circ} \mathrm{C}, 1 \mathrm{~h}\right.$; light striped bars). Media were exchanged after heat shock, and cells recovered for $24 \mathrm{~h}$. Media were then harvested for ELISA analyses for HSP27 (A) and HSP70 $(\boldsymbol{B})$ using commercial kits. Statistical differences in HSP output were determined using $t$ tests, with the $p$ values indicated by asterisks. Those unmarked were not significant. SDs of replicate measurements were always $<10 \%$ of the average and would be essentially unreadable as error bars; thus, they are not shown.

stress-induced chaperone/HSP production, relocation, and release might make the tumors cells noticeable to the immune system of the syngeneic host. Thus, $24 \mathrm{~h}$ after the standard heat shock regimen (i.e., $1 \mathrm{~h}$ heat shock, $24 \mathrm{~h}$ recovery), we injected groups of VM/Dk mice with 100,000 heat-shocked SMA560 cells or equal numbers of non-heat-shocked cells. Cell viability was equivalent for both groups before tumor implantation. We then followed tumor progression over time. Figure $8 \mathrm{~A}$ shows that by day 42 after tumor inoculation, there is a significant difference in tumor burden between the groups; the mice inoculated with the heat-shocked tumor cells rejected their tumors (the tumors simply did not grow), whereas the mice that received cells cultured at normal temperature grew tumors, until it was necessary to kill the animals (in the experiment shown, typical of two performed, in the group that received the non-heat-shocked tumor inoculum, the single mouse that had not developed tumor at this time point did eventually grow a tumor and had to be killed by day 90). To rule out the possibility that in vivo viability of the two groups of cells was different, we repeated the experiment using immune- incompetent athymic (nude) mice as tumor cell recipients. In those hosts, heat-shocked and non-heat-shocked cells generated tumors with the same growth kinetics and at more than twice the rate of immune-competent animals (large tumors by day 22) (Fig. $8 \mathrm{~B}$ ). This also suggests that an immune mechanism may be responsible for the rejection of the stressed tumor cells. Tumorfree mice were rechallenged with viable (non-heat-shocked) SMA560 cells $90 \mathrm{~d}$ after the initial tumor implantation; all of the previously tumor-free mice developed tumors, indicating a lack of memory response (data not shown).

\section{Direct immunization with SMA560-derived chaperone} proteins results in immune responses against a brain tumor antigen, as well as reduced tumor burden in vaccinated mice Because HSPs are implicated in this immune response against heat-stressed tumor cells, we generated CRCL from SMA560 tumors for use as a vaccine (Graner et al., 2000, 2003; Kislin et al., 2007). In this vaccine scenario, tumor-derived HSPs are seen as couriers of antigenic peptides as well as entities that provide stimulation to professional antigen presenting cells, resulting in better T-cell activation (Graner and Bigner, 2005). Mice were immunized with this tumor-derived, HSP-based vaccine, providing them with the immune stimulus of the exogenous HSPs (as might be found on the tumor surface or released from the heat-shocked cells), and the tumor antigen content of the HSP-escorted peptides. Ex vivo restimulation of the primed splenocytes with the vaccine, or with known brain tumor antigen peptides [from GPNMB (Kuan et al., 2006)], elicited interferon- $\gamma$ secretion from the cells (Fig. 9). In vivo VM/Dk mice bearing pre-established SMA560 tumors that received therapeutic vaccine treatment also exhibited significantly reduced tumor burdens compared with mock-treated animals (Fig. 10), thus further demonstrating that tumor-derived HSPs are capable of driving antitumor responses in this model, consistent with experiments in a number of other mouse tumors (Graner et al., 2003). It should be noted that the $\mathrm{VM} / \mathrm{Dk}$ mouse strain is susceptible to experimental allergic encephalomyelitis (Heimberger et al., 2000); nonetheless, neither the mice receiving the heat-shocked tumor cells nor those receiving the CRCL vaccines showed any signs of neurologic damage.

\section{Discussion}

Whereas there have been many publications on heat shock protein expression and heat stress characterization in a wide variety of tumor cell types (Ciocca and Calderwood, 2005; Calderwood et al., 2006; Li and Lee, 2006), such studies are rare in brain tumors (Fuse, 1991; Hermisson et al., 2000; J. Wang et al., 2006). To our knowledge, this may be the first to examine chaperone/ HSP expression in brain tumor cell lines from the intracellular and also the cell surface/extracellular perspectives. Through this we may gain insight into the stress responses of brain tumors, with the overriding goal of identifying targets, pathways, or vulnerabilities in these tumors.

Western blot characterizations of heat-stressed cells show that different brain tumor cell lines vary substantially in their heat shock responses as quantified by increases in HSP production. Whereas we have examined by Western blot the expression of HSP70 family members in more than a dozen brain tumor cell lines and/or xenografts, the experiments in this report used a limited number of cell lines; however, our selections indicate that at least some brain tumor cells are capable of extensive HSP output after heat stress (Fig. 1B,D, lines D392MG and SMA560), whereas lines such as D54MG and D341MED do not respond as vigorously. However, these latter two lines show impressive in- 
A

\section{D54MG exosomes}

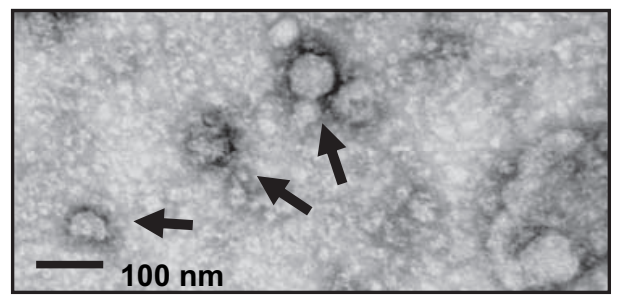

\section{SMA560 exosomes}

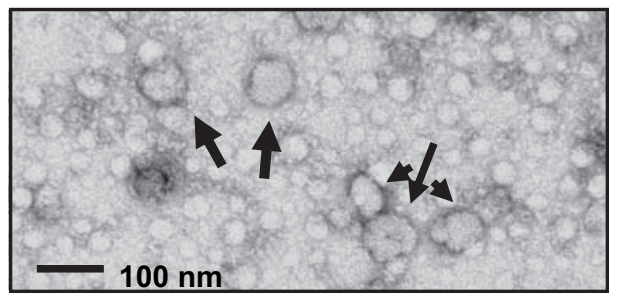

B

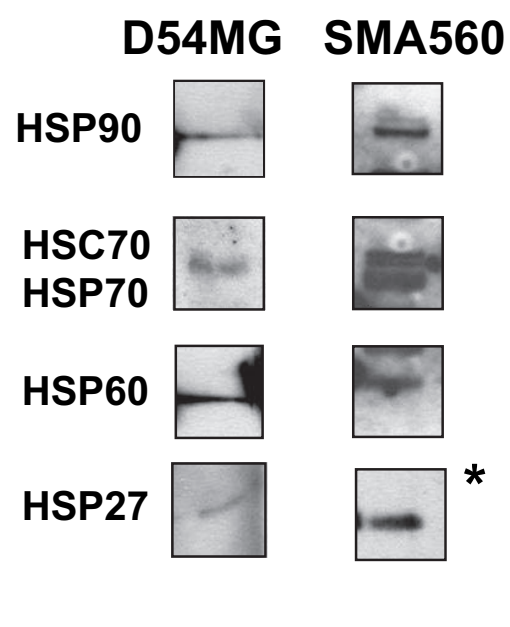

Figure 7. Brain tumor cell lines release exosomes into the media. Exosomes were isolated from the spent media from cell lines D54MG and SMA560 by differential centrifugation. $A$, Exosomes recovered in the final pellets were observed by electron microscopy after uranyl acetate negative staining (arrows). $\boldsymbol{B}$, Western blots of exosome material show that HSPs 90, 70, 60, and 27 are present. For the SMA560 line, the asterisk indicates a rodent mitochondrial small HSP of $\sim 37 \mathrm{kDa}$ rather than the expected $20-30 \mathrm{kDa}$.

plied stress response proteins to protect the neurons from injury; curiously, those "model" glial cells were actually the brain tumor cell line T98G, which also showed substantial heat shock responses in HSP70 induction (Guzhova et al., 2001). This HSP70 release has been postulated to occur via exosomes (Tytell, 2005). Thus, brain tumors may have innate mechanisms for the cell surface/extracellular HSP localization. We are conducting additional biochemical and biological characterizations of these exosomes. We believe that these are the first reports of a number of cell surface HSPs, cochaperones, and exosomes in brain tumor cell lines, although HSP70 has been identified on patient glioma cell surfaces (Multhoff et al., 2001).

Cell surface/extracellular HSPs may have important immune implications (Asea, 2005; Calderwood et al., 2005; Fleshner and Johnson, 2005; Korbelik and Sun, 2005). Preclinical vaccine models featuring surface HSP expression, whether driven by transfected genetic constructs (Zheng et al., 2001; Chen et al., 2002) or by

ducible expression of HSPs 27, 70, and 90 in the absence of heat stress (Fig. $1 A, C$ ). The significance of this upregulated HSP expression is unclear, but it suggests that these tumor cells adapted a constitutive stress response despite the seemingly benign conditions of tissue culture, and this high expression of inducible HSPs is evident in in vivo-grown tumors as well (Fig. 2, 3). The lack of nuclear HSP localization (Fig. 3) also suggests a lack of a true stress response while nonetheless having heightened HSP levels. The molecular nature and mechanism of the brain tumor cellular stress responses will be intriguing to explore.

Cell surface chaperone/heat shock proteins are routinely identified (Multhoff and Hightower, 1996; Eustace and Jay, 2004; Radons and Multhoff, 2005; Schmitt et al., 2007), but this remains unstudied in brain tumor cells. Here we have shown that several HSPs, and at least one cochaperone, are expressed on the surfaces of brain tumor cell lines (Figs. 4, 5, Table 1). For the lines examined, this localization occurs without heat stress, but heat shock tends to increase the numbers of membrane HSPs (Table 1). In the D54MG and D341MED cells (which show little additional HSP induction after heat shock), it may be that the additional cell surface display of HSPs results from relocation of the HSPs as opposed to additional expression. Supplemental Table 1 (available at www.jneurosci.org as supplemental material) lists almost two dozen brain tumor cell lines and xenografts that express some form of chaperones/HSPs on cell surfaces; in some cases, there are numerous HSP family members displayed on the cell membranes.

In addition to HSPs on brain tumor cell surfaces, we also demonstrated that at least HSPs 27 and/or 70 were shed from brain tumor cells into the media. The release mechanism is unknown, but herein we did show that exosomes are shed into the spent media of brain tumor cell lines (Fig. 7, D54MG and SMA560) [we have additional data for eight more cell lines (A. Dechkovskaia and N. Satterwhite, unpublished observations)]. Extracellular release of HSP70 by glial cells was previously described as a defense mechanism whereby neurons may be sup- the propensity of a given cell line to surface localize HSPs (Wang et al., 2004) were capable of generating antitumor immune responses. Other strategies used secretable chaperones and HSPs (again, artificially constructed or "naturally occurring" in certain tissue culture cells), successfully immunizing animals against tumor challenge (Yamazaki et al., 1999; X. Y. Wang et al., 2006). Also, stress induction resulting in surface HSP expression followed by apoptosis-inducing therapeutics yielded a potent vaccine, whereas nonstressed apoptotic cells were nonimmunogenic (Feng et al., 2001). SMA560 displayed cell surface and extracellular HSP deposition after heat stress, and it is one of the few truly syngeneic murine brain tumor models; therefore, we tested the effects of heat shock on the tumorigenicity of those cells. Sublethal heat shock $\left(42^{\circ}, 1 \mathrm{~h} ; 24 \mathrm{~h}\right.$ recovery) completely abrogated the tumorigenicity of the SMA560 cells after subsequent injection into syngeneic VM/Dk mice but had no effect on SMA560 tumors grown in nude mice (Fig. 8). Given the changes in the cell surface HSP phenotype, as well as the extracellular HSP70 release by these cells after heat shock, one is tempted to connect the tumor HSP expression/localization to the stimulation of an antitumor immune response. The stimulatory effects of HSPs on antigenpresenting cells is well appreciated (Binder et al., 2004; Facciponte et al., 2005; Zeng et al., 2006a), and the targeting of cell surface HSPs by NK cells and $\gamma \delta$ T-cells is known (Harada et al., 1998; Multhoff, 2002). However, the cellular heat shock response is a complex phenomenon engaging a number of metabolic and genetic aspects (Hirsch et al., 2006), including chromatin remodeling (Uffenbeck and Krebs, 2006) and lipid alterations (Jenkins, 2003). Thus, there may be a variety of stress-related immune activators that could trigger responses against stressed tumor cells.

We began our initial dissection of possible immune-effector mechanisms by using athymic (nude) mice as tumor recipients of heat-shocked tumor cells (or of control, non-heat-shocked cells). Both groups of tumor cells grew at equal rates in immune compromised mice, indicating that T-cells may play an important 


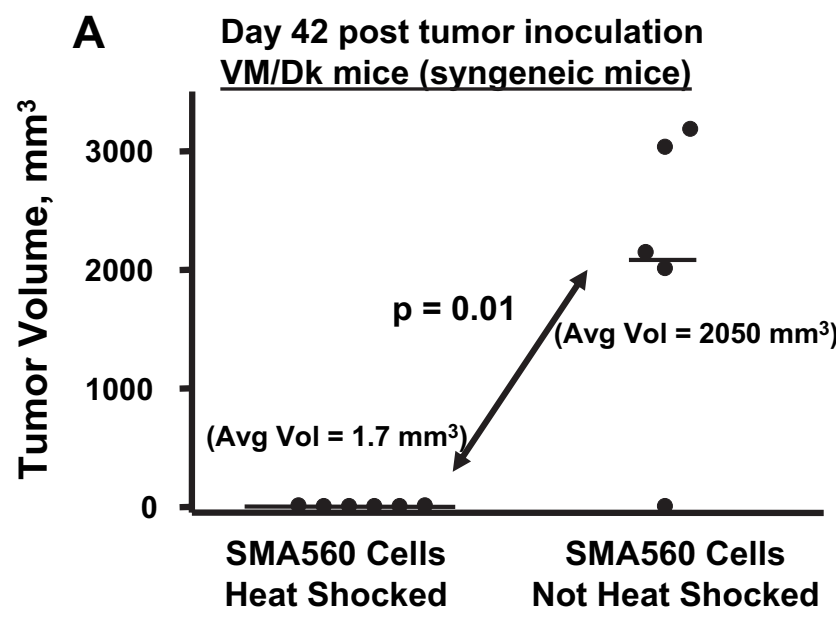

B

$$
\begin{aligned}
& \text { Day } 22 \text { post tumor inoculation } \\
& \text { nu/nu (athymic) mice }
\end{aligned}
$$

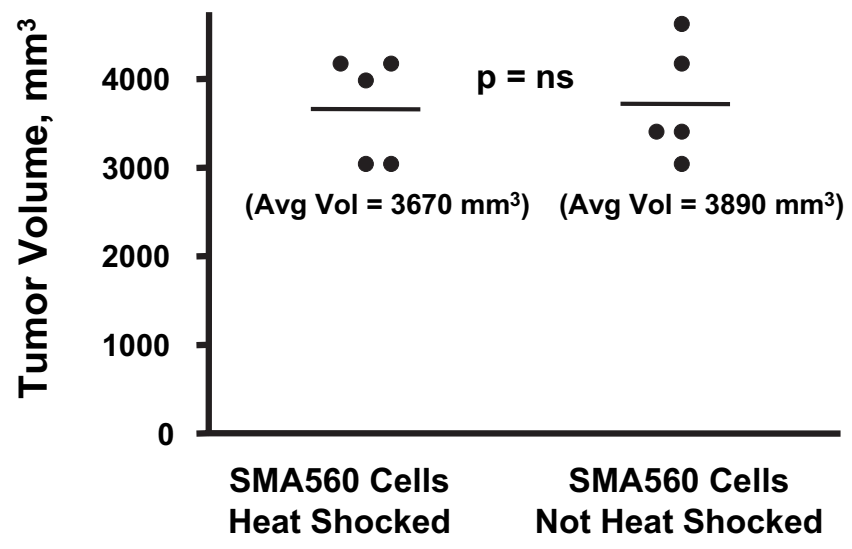

Figure 8. Heat-shocked SMA560 cells show reduced tumorigenicity in immune-competent syngeneic mice. SMA560 cells were heat shocked $\left(42^{\circ} \mathrm{C}, 1 \mathrm{~h}\right)$ or were left untreated. $A$, After a $24 \mathrm{~h}$ recovery, groups of $5 \mathrm{VM} / \mathrm{Dk}$ mice were injected with 100,000 cells, either heat shocked or untreated, subcutaneously into the right flanks, and tumor volumes were measured $42 \mathrm{~d}$ later. Cells in both groups were of equal viability. $p$ value ( $t$ test) between heat-shocked cell tumor growth versus control is shown. In this experiment, the solitary mouse in the control group without tumor later grew one and had to be killed $90 \mathrm{~d}$ after tumor inoculation. $\boldsymbol{B}$, The same heat shock experiment was conducted using immunoincompetent athymic (nu/nu) mice as tumor recipients. Both heat-shocked and non-heat-shocked tumor cells grew in nude mice at statistically indistinguishable rates ( $p$ value, not significant), and mice were killed on day 22.

role in the recognition and eradication of the heat-shocked tumor cells (nude mice lack T-cells but have semifunctional macrophage, B cells, and NK cells). Whereas NK cells may be stimulated by exogenous or extracellular HSPs, they may require additional cytokine support from T-cells to be fully activated. The reciprocal cytokine signaling may also be true (Zeng et al., 2006b). In our follow-up studies, syngeneic mice that remained tumor-free after rejection of the heat-treated SMA560 cells remained susceptible to rechallenge (90 d after the initial tumor challenge) by nonstressed SMA560 cells (data not shown). This indicates a lack of memory responses against the tumor and suggests that the innate immune-effector cells may play an important role in eradication of the stressed tumor cells; such lack of memory responses was seen previously in an HSP70 vaccine setting (Kumaraguru et al., 2002). The mechanism of this putative immune response in this model is an active area of investigation,

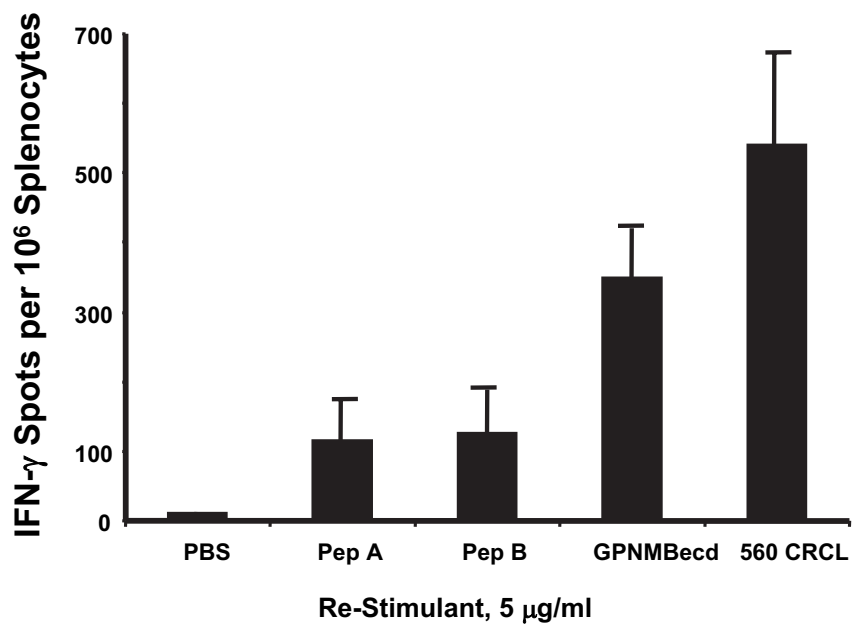

Figure 9. Mice receiving brain tumor-derived CRCL vaccines develop specific splenocyte reactivity against brain tumor antigens as well as against undefined antigens within the whole vaccine. VM/Dk mice were vaccinated on day -14 and day -7 with $20 \mu \mathrm{g}$ of SMA560-derived CRCL each time. On day 0, splenocytes were harvested, plated, and restimulated with the antigens shown (GPNMBecd; Pep A and Pep B are GPNMB 18-mer and 22-mer peptides, respectively; see Materials and Methods for sequences). Restimulation was with antigen concentrations of $5 \mu \mathrm{g} / \mathrm{ml}$. Interferon- $\gamma$ output was quantified by ELISPOT assay; shown are averages and SD of triplicate wells. Error bars represent SEM.

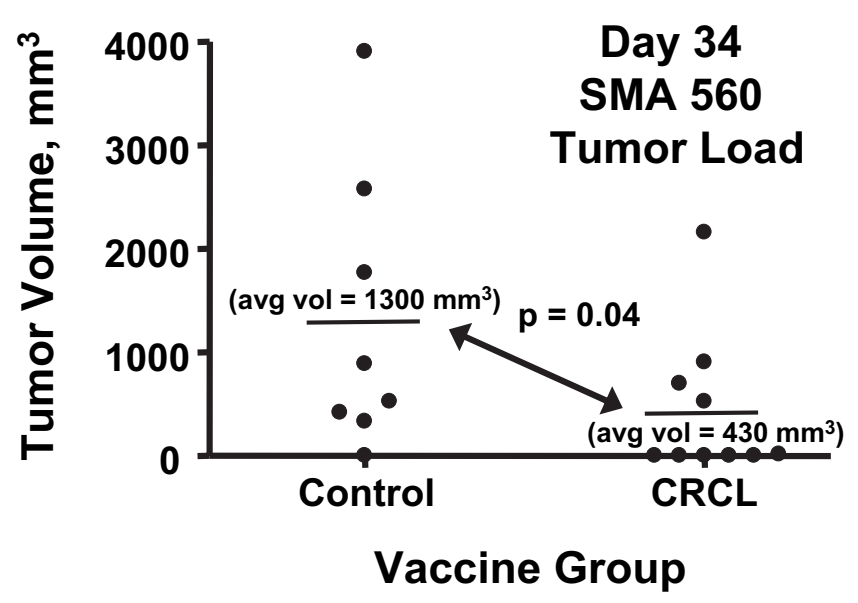

Figure 10. Vaccination with SMA560 CRCL reduces tumor burden in syngeneic, tumorbearing mice. Groups of VM/Dk mice (10 per group, initially) were inoculated subcutaneously with 100,000 SMA60 cells. Five days later, one group of mice received subcutaneous injections of $C R C L$ vaccines $(50 \mu \mathrm{g})$ derived from SMA560 tumor. Control mice received equal volumes of saline. Injections were given on the flank opposite the tumor, and tumor growth was monitored thereafter. Before day 34, two mice in the control group had died from their tumors, and their tumor volumes were censored from the averages and statistics shown here. avg vol, Average volume.

with particular focus on intracranial implantation of the stressed/ nonstressed tumors to assess the effect of orthotopic microenvironment and immunity. "Immune privilege" of the CNS is no longer viewed as a barrier to achieving immune reactions in the brain (Galea et al., 2007), and it is clear that immune-effector cells are able to enter such regions, albeit with some interesting biological constraints (Mrass and Weninger, 2006). Thus, additional study will be necessary to determine the roles and relationships of the potential effector cells and mechanisms.

Arguably, the best-studied heat shock protein is the stressinducible HSP70, and it has received the most focus at the cell surface/extracellular aspect (Radons and Multhoff, 2005). As a 
Table 2. Summary of inducible HSP70 expression in select brain tumor cell lines (relative to unstressed cells or to non-HSP expression such as actin)

\begin{tabular}{|c|c|c|c|c|c|c|}
\hline \multirow[t]{2}{*}{ Cell line } & \multicolumn{2}{|c|}{ HSP70 expression (Western blot) } & \multicolumn{2}{|c|}{$\begin{array}{l}\text { Cell surface HSP70 expression (flow } \\
\text { cytometry) }\end{array}$} & \multicolumn{2}{|c|}{ Extracellular HSP70 release (ELISA) } \\
\hline & Constitutive & Heat stress & Constitutive & Heat stress & Constitutive & Heat stress \\
\hline $\begin{array}{l}\text { D54MG derived from line A172, adult malignant } \\
\text { glioma }\end{array}$ & + & ++ & + & ++ & + & ++ \\
\hline D392MG adult malignant glioma & $+/-$ & +++ & ++ & +++ & ++ & +++ \\
\hline D341MED pediatric medulloblastoma & ++ & $+1-$ & + & ++ & + & +++ \\
\hline $\begin{array}{l}\text { SMA560 murine anaplastic astrocytoma, } \\
\text { syngeneic to VM/Dk strain }\end{array}$ & $+1-$ & +++ & $+1-$ & ++ & + & ++++ \\
\hline
\end{tabular}

$+/-$, Detectable expression; + , moderate expression; $++\rightarrow++++$, high to very high expression.

cell surface tumor marker, it has been the target of NK cell therapy (Krause et al., 2004), but it may also be targetable by other means, such as ligands or antibodies, on the basis of the tumorspecific expression of surface HSP70. Whereas HSP70 is surely not the sole chaperone immune modulator of the tumor cell surface, it is undoubtedly important, so we have included a summary table of inducible HSP70 expression in the cell lines used in this work (Table 2).

There are numerous publications concerning the immunity of the chaperones, particularly as vaccines when those proteins are purified from tumor sources (for review, see Srivastava, 2002, 2006; Graner and Bigner, 2005; Zeng et al., 2006a) but none from brain tumor models. Here, we have used CRCL as a tumorderived HSP-based vaccine (Graner et al., 2000, 2003; Kislin et al., 2007) against the SMA560 tumor. Injection of exogenous SMA560 CRCL may be comparable with the release of tumor chaperones after heat stress. The vaccine promoted specific immune responses ex vivo and resulted in significant antitumor activity in vivo against pre-established tumors (Figs. 9, 10). Whereas this vaccine is a complex mixture of chaperones, cochaperones, and other proteins, we have previously demonstrated the critical nature of the HSPs at promoting antitumor immune responses (Zeng et al., 2003; Kislin et al., 2007). In this report, we have focused on the stress biology of brain tumors and the implications for immune responses, but there is strong precedent in the cancer vaccine field for continuing attention to HSP-based approaches given the abilities of surface/extracellular/ exogenous HSPs to provoke immune responses and carry antigens (Graner and Bigner, 2005).

We hope that this broad initial characterization of chaperone/ heat shock proteins in these brain tumor cell lines and their demonstration of vaccine potential will provide impetus for additional studies, particularly in light of increased interest in HSP90 inhibitors as cancer chemotherapeutics (Neckers and Neckers, 2005; Cullinan and Whitesell, 2006; Graner and Bigner, 2006) and the use of tumor-derived chaperone vaccines against brain tumors in a phase I/II clinical trial (http://www.clinicaltrials.gov/ $\mathrm{ct} /$ show/NCT00293423?order $=1$ ). Neuro-oncology may yet benefit from the study of and potential therapeutic applications of chaperones/HSPs against these recalcitrant malignancies.

\section{References}

Arap MA, Lahdenranta J, Mintz PJ, Hajitou A, Sarkis AS, Arap W, Pasqualini $\mathrm{R}$ (2004) Cell surface expression of the stress response chaperone GRP78 enables tumor targeting by circulating ligands. Cancer Cell 6:275-284.

Asea A (2005) Stress proteins and initiation of immune response: chaperokine activity of hsp72. Exerc Immunol Rev 11:34-45.

Bausero MA, Page DT, Osinaga E, Asea A (2004) Surface expression of Hsp25 and Hsp72 differentially regulates tumor growth and metastasis. Tumour Biol 25:243-251.
Binder RJ, Vatner R, Srivastava P (2004) The heat-shock protein receptors: some answers and more questions. Tissue Antigens 64:442-451.

Bullard DE, Schold Jr SC, Bigner SH, Bigner DD (1981) Growth and chemotherapeutic response in athymic mice of tumors arising from human glioma-derived cell lines. J Neuropathol Exp Neurol 40:410-427.

Burdon RH (1987) Temperature and animal cell protein synthesis. Symp Soc Exp Biol 41:113-133.

Calderwood SK, Theriault JR, Gong J (2005) Message in a bottle: role of the $70-\mathrm{kDa}$ heat shock protein family in anti-tumor immunity. Eur J Immunol 35:2518-2527.

Calderwood SK, Khaleque MA, Sawyer DB, Ciocca DR (2006) Heat shock proteins in cancer: chaperones of tumorigenesis. Trends Biochem Sci $31: 164-172$.

Chaput N, Taieb J, Schartz NE, Andre F, Angevin E, Zitvogel L (2004) Exosome-based immunotherapy. Cancer Immunol Immunother 53:234-239.

Chen B, Wang JF, Young LT (2000) Chronic valproate treatment increases expression of endoplasmic reticulum stress proteins in the rat cerebral cortex and hippocampus. Biol Psychiatry 48:658-664.

Chen W, Wang J, Shao C, Liu S, Yu Y, Wang Q, Cao X (2006) Efficient induction of antitumor $\mathrm{T}$ cell immunity by exosomes derived from heatshocked lymphoma cells. Eur J Immunol 36:1598-1607.

Chen X, Tao Q, Yu H, Zhang L, Cao X (2002) Tumor cell membrane-bound heat shock protein 70 elicits antitumor immunity. Immunol Lett 84:81-87.

Ciocca DR, Calderwood SK (2005) Heat shock proteins in cancer: diagnostic, prognostic, predictive, and treatment implications. Cell Stress Chaperones 10:86-103.

Clayton A, Turkes A, Navabi H, Mason MD, Tabi Z (2005) Induction of heat shock proteins in B-cell exosomes. J Cell Sci 118:3631-3638.

Craig EA (1985) The heat shock response. CRC Crit Rev Biochem 18:239-280.

Cullinan SB, Whitesell L (2006) Heat shock protein 90: a unique chemotherapeutic target. Semin Oncol 33:457-465.

Davidson DJ, Haskell C, Majest S, Kherzai A, Egan DA, Walter KA, Schneider A, Gubbins EF, Solomon L, Chen Z, Lesniewski R, Henkin J (2005) Kringle 5 of human plasminogen induces apoptosis of endothelial and tumor cells through surface-expressed glucose-regulated protein 78. Cancer Res 65:4663-4672.

Downs CA, Jones LR, Heckathorn SA (1999) Evidence for a novel set of small heat-shock proteins that associates with the mitochondria of murine PC12 cells and protects NADH:ubiquinone oxidoreductase from heat and oxidative stress. Arch Biochem Biophys 365:344-350.

Dunlop ME, Muggli EE (2000) Small heat shock protein alteration provides a mechanism to reduce mesangial cell contractility in diabetes and oxidative stress. Kidney Int 57:464-475.

Edinger AL (2005) Growth factors regulate cell survival by controlling nutrient transporter expression. Biochem Soc Trans 33:225-227.

Escola JM, Kleijmeer MJ, Stoorvogel W, Griffith JM, Yoshie O, Geuze HJ (1998) Selective enrichment of tetraspan proteins on the internal vesicles of multivesicular endosomes and on exosomes secreted by human B-lymphocytes. J Biol Chem 273:20121-20127.

Eustace BK, Jay DG (2004) Extracellular roles for the molecular chaperone, hsp90. Cell Cycle 3:1098-1100.

Evdonin AL, Martynova MG, Bystrova OA, Guzhova IV, Margulis BA, Medvedeva ND (2006) The release of Hsp70 from A431 carcinoma cells is mediated by secretory-like granules. Eur J Cell Biol 85:443-455. 
Facciponte JG, MacDonald IJ, Wang XY, Kim H, Manjili MH, Subjeck JR (2005) Heat shock proteins and scavenger receptors: role in adaptive immune responses. Immunol Invest 34:325-342.

Faure J, Lachenal G, Court M, Hirrlinger J, Chatellard-Causse C, Blot B, Grange J, Schoehn G, Goldberg Y, Boyer V, Kirchhoff F, Raposo G, Garin J, Sadoul R (2006) Exosomes are released by cultured cortical neurones. Mol Cell Neurosci 31:642-648.

Feng H, Zeng Y, Whitesell L, Katsanis E (2001) Stressed apoptotic tumor cells express heat shock proteins and elicit tumor-specific immunity. Blood 97:3505-3512.

Fleshner M, Johnson JD (2005) Endogenous extra-cellular heat shock protein 72: releasing signal(s) and function. Int J Hyperthermia 21:457-471.

Friedman HS, Burger PC, Bigner SH, Trojanowski JQ, Brodeur GM, He XM, Wikstrand CJ, Kurtzberg J, Berens ME, Halperin EC, Bigner DD (1988) Phenotypic and genotypic analysis of a human medulloblastoma cell line and transplantable xenograft (D341 Med) demonstrating amplification of c-myc. Am J Pathol 130:472-484.

Fuse T (1991) Alterations in cytokinetics and heat shock protein $(70 \mathrm{kDa})$ expression of glial cell by hyperthermia (in Japanese). No To Shinkei 43:843-850.

Galea I, Bechmann I, Perry VH (2007) What is immune privilege (not)? Trends Immunol 28:12-18.

Garrido C, Schmitt E, Cande C, Vahsen N, Parcellier A, Kroemer G (2003) HSP27 and HSP70: potentially oncogenic apoptosis inhibitors. Cell Cycle 2:579-584.

Gass P, Schroder H, Prior P, Kiessling M (1994) Constitutive expression of heat shock protein 90 (HSP90) in neurons of the rat brain. Neurosci Lett 182:188-192.

Gething MJ, Sambrook J (1992) Protein folding in the cell. Nature 355:33-45.

Gottwald E, Herschbach M, Lahni B, Miesfeld RL, Kunz S, Raynes DA, Guerriero V (2006) Expression of the cochaperone HspBP1 is not coordinately regulated with Hsp70 expression. Cell Biol Int 30:553-558.

Graner M, Raymond A, Akporiaye E, Katsanis E (2000) Tumor-derived multiple chaperone enrichment by free-solution isoelectric focusing yields potent antitumor vaccines. Cancer Immunol Immunother 49:476-484.

Graner MW, Bigner DD (2005) Chaperone proteins and brain tumors: potential targets and possible therapeutics. Neuro Oncol 7:260-278.

Graner MW, Bigner DD (2006) Therapeutic aspects of chaperones/heatshock proteins in neuro-oncology. Expert Rev Anticancer Ther 6:679-695.

Graner MW, Zeng Y, Feng H, Katsanis E (2003) Tumor-derived chaperonerich cell lysates are effective therapeutic vaccines against a variety of cancers. Cancer Immunol Immunother 52:226-234.

Griguer CE, Oliva CR, Gillespie GY (2005) Glucose metabolism heterogeneity in human and mouse malignant glioma cell lines. J Neurooncol 74:123-133.

Griguer CE, Oliva CR, Kelley EE, Giles GI, Lancaster Jr JR, Gillespie GY (2006) Xanthine oxidase-dependent regulation of hypoxia-inducible factor in cancer cells. Cancer Res 66:2257-2263.

Guzhova I, Kislyakova K, Moskaliova O, Fridlanskaya I, Tytell M, Cheetham M, Margulis B (2001) In vitro studies show that Hsp70 can be released by glia and that exogenous Hsp70 can enhance neuronal stress tolerance. Brain Res 914:66-73.

Harada M, Kimura G, Nomoto K (1998) Heat shock proteins and the antitumor T cell response. Biotherapy 10:229-235.

Harguindey S, Orive G, Luis Pedraz J, Paradiso A, Reshkin SJ (2005) The role of $\mathrm{pH}$ dynamics and the $\mathrm{Na}+/ \mathrm{H}+$ antiporter in the etiopathogenesis and treatment of cancer. Two faces of the same coin-one single nature. Biochim Biophys Acta 1756:1-24.

Hegmans JP, Bard MP, Hemmes A, Luider TM, Kleijmeer MJ, Prins JB, Zitvogel L, Burgers SA, Hoogsteden HC, Lambrecht BN (2004) Proteomic analysis of exosomes secreted by human mesothelioma cells. Am J Pathol 164:1807-1815.

Heimberger AB, Crotty LE, Archer GE, McLendon RE, Friedman A, Dranoff G, Bigner DD, Sampson JH (2000) Bone marrow-derived dendritic cells pulsed with tumor homogenate induce immunity against syngeneic intracerebral glioma. J Neuroimmunol 103:16-25.

Hermisson M, Strik H, Rieger J, Dichgans J, Meyermann R, Weller M (2000) Expression and functional activity of heat shock proteins in human glioblastoma multiforme. Neurology 54:1357-1365.
Hightower LE, Guidon Jr PT (1989) Selective release from cultured mammalian cells of heat-shock (stress) proteins that resemble glia-axon transfer proteins. J Cell Physiol 138:257-266.

Hirsch C, Gauss R, Sommer T (2006) Coping with stress: cellular relaxation techniques. Trends Cell Biol 16:657-663.

Itoh H, Tashima Y, Eishi Y, Okeda R (1993) Localization of HSP90 in rat brain. Int J Biochem 25:93-99.

Jenkins GM (2003) The emerging role for sphingolipids in the eukaryotic heat shock response. Cell Mol Life Sci 60:701-710.

Johnstone RM (2006) Exosomes biological significance: a concise review. Blood Cells Mol Dis 36:315-321.

Kamal A, Boehm MF, Burrows FJ (2004) Therapeutic and diagnostic implications of Hsp90 activation. Trends Mol Med 10:283-290.

Kato H, Kogure K, Liu XH, Araki T, Kato K, Itoyama Y (1995) Immunohistochemical localization of the low molecular weight stress protein HSP27 following focal cerebral ischemia in the rat. Brain Res 679:1-7.

Kato S, Hirano A, Kato M, Herz F, Ohama E (1993) Comparative study on the expression of stress-response protein $(\operatorname{srp}) 72, \operatorname{srp} 27$, alpha B-crystallin and ubiquitin in brain tumours. An immunohistochemical investigation. Neuropathol Appl Neurobiol 19:436-442.

Kato S, Kato M, Hirano A, Takikawa M, Ohama E (2001) The immunohistochemical expression of stress-response protein (srp) 60 in human brain tumours: relationship of srp 60 to the other five srps, proliferating cell nuclear antigen and p53 protein. Histol Histopathol 16:809-820.

Kaul SC, Matsui M, Takano S, Sugihara T, Mitsui Y, Wadhwa R (1997) Expression analysis of mortalin, a unique member of the Hsp70 family of proteins, in rat tissues. Exp Cell Res 232:56-63.

Keller S, Sanderson MP, Stoeck A, Altevogt P (2006) Exosomes: from biogenesis and secretion to biological function. Immunol Lett 107:102-108.

Kislin KL, Marron MT, Li G, Graner MW, Katsanis E (2007) Chaperonerich cell lysate embedded with BCR-ABL peptide demonstrates enhanced anti-tumor activity against a murine BCR-ABL positive leukemia. FASEB J 21:2173-2184.

Korbelik M, Sun J (2006) Photodynamic therapy-generated vaccine for cancer therapy. Cancer Immunol Immunother 55:900-909.

Krause SW, Gastpar R, Andreesen R, Gross C, Ullrich H, Thonigs G, Pfister K, Multhoff G (2004) Treatment of colon and lung cancer patients with ex vivo heat shock protein 70-peptide-activated, autologous natural killer cells: a clinical phase i trial. Clin Cancer Res 10:3699-3707.

Kuan CT, Wikstrand CJ, Archer G, Beers R, Pastan I, Zalutsky MR, Bigner DD (2000) Increased binding affinity enhances targeting of glioma xenografts by EGFRvIII-specific scFv. Int J Cancer 88:962-969.

Kuan CT, Wakiya K, Dowell JM, Herndon II JE, Reardon DA, Graner MW, Riggins GJ, Wikstrand CJ, Bigner DD (2006) Glycoprotein nonmetastatic melanoma protein $\mathrm{B}$, a potential molecular therapeutic target in patients with glioblastoma multiforme. Clin Cancer Res 12:1970-1982.

Kumaraguru U, Gierynska M, Norman S, Bruce BD, Rouse BT (2002) Immunization with chaperone-peptide complex induces low-avidity cytotoxic $\mathrm{T}$ lymphocytes providing transient protection against herpes simplex virus infection. J Virol 76:136-141.

Lancaster GI, Febbraio MA (2005) Mechanisms of stress-induced cellular HSP72 release: implications for exercise-induced increases in extracellular HSP72. Exerc Immunol Rev 11:46-52.

Langer T, Rosmus S, Fasold H (2003) Intracellular localization of the 90 $\mathrm{kDA}$ heat shock protein (HSP90alpha) determined by expression of a EGFP-HSP90alpha-fusion protein in unstressed and heat stressed 3T3 cells. Cell Biol Int 27:47-52.

Li J, Lee AS (2006) Stress induction of GRP78/BiP and its role in cancer. Curr Mol Med 6:45-54.

Lindquist S, Craig EA (1988) The heat-shock proteins. Annu Rev Genet 22:631-677.

Mambula SS, Calderwood SK (2006) Heat shock protein 70 is secreted from tumor cells by a nonclassical pathway involving lysosomal endosomes. J Immunol 177:7849-7857.

Manzerra P, Brown IR (1996) The neuronal stress response: nuclear translocation of heat shock proteins as an indicator of hyperthermic stress. Exp Cell Res 229:35-47.

Mears R, Craven RA, Hanrahan S, Totty N, Upton C, Young SL, Patel P, Selby PJ, Banks RE (2004) Proteomic analysis of melanoma-derived exosomes by two-dimensional polyacrylamide gel electrophoresis and mass spectrometry. Proteomics 4:4019-4031.

Mrass P, Weninger W (2006) Immune cell migration as a means to control 
immune privilege: lessons from the CNS and tumors. Immunol Rev 213:195-212.

Multhoff G (2002) Activation of natural killer cells by heat shock protein 70. Int J Hyperthermia 18:576-585.

Multhoff G, Hightower LE (1996) Cell surface expression of heat shock proteins and the immune response. Cell Stress Chaperones 1:167-176.

Multhoff G, Pfister K, Gehrmann M, Hantschel M, Gross C, Hafner M, Hiddemann W (2001) A 14-mer Hsp70 peptide stimulates natural killer (NK) cell activity. Cell Stress Chaperones 6:337-344.

Neckers L, Neckers K (2005) Heat-shock protein 90 inhibitors as novel cancer chemotherapeutics-an update. Expert Opin Emerg Drugs 10:137-149.

Ostrowski LE, von Wronski MA, Bigner SH, Rasheed A, Schold Jr SC, Brent TP, Mitra S, Bigner DD (1991) Expression of O6-methylguanine-DNA methyltransferase in malignant human glioma cell lines. Carcinogenesis 12:1739-1744.

Papp D, Prohaszka Z, Kocsis J, Fust G, Banhegyi D, Raynes DA, Guerriero V (2005) Development of a sensitive assay for the measurement of antibodies against heat shock protein binding protein 1 (HspBP1): increased levels of anti-HspBP1 IgG are prevalent in HIV infected subjects. J Med Virol 76:464-469.

Plumier JC, Hopkins DA, Robertson HA, Currie RW (1997) Constitutive expression of the $27-\mathrm{kDa}$ heat shock protein (Hsp27) in sensory and motor neurons of the rat nervous system. J Comp Neurol 384:409-428.

Preissig SH, Pegram CN, Bigner DD (1979) Cytopathologic characteristics of permanent cell lines derived from anaplastic human gliomas. Acta Cytol 23:412-419.

Radons J, Multhoff G (2005) Immunostimulatory functions of membranebound and exported heat shock protein 70. Exerc Immunol Rev 11:17-33.

Raynes DA, Guerriero Jr V (1998) Inhibition of Hsp70 ATPase activity and protein renaturation by a novel Hsp70-binding protein. J Biol Chem 273:32883-32888.

Raynes DA, Graner MW, Bagatell R, McLellan C, Guerriero V (2003) Increased expression of the Hsp70 cochaperone HspBP1 in tumors. Tumour Biol 24:281-285.

Sampson JH, Ashley DM, Archer GE, Fuchs HE, Dranoff G, Hale LP, Bigner DD (1997) Characterization of a spontaneous murine astrocytoma and abrogation of its tumorigenicity by cytokine secretion. Neurosurgery 41:1365-1373.

Schmitt E, Gehrmann M, Brunet M, Multhoff G, Garrido C (2007) Intracellular and extracellular functions of heat shock proteins: repercussions in cancer therapy. J Leukoc Biol 81:15-27.

Serano RD, Pegram CN, Bigner DD (1980) Tumorigenic cell culture lines from a spontaneous VM/Dk murine astrocytoma (SMA). Acta Neuropathol (Berl) 51:53-64.

Srivastava P (2002) Interaction of heat shock proteins with peptides and antigen presenting cells: chaperoning of the innate and adaptive immune responses. Annu Rev Immunol 20:395-425.

Srivastava PK (2006) Therapeutic cancer vaccines. Curr Opin Immunol 18:201-205.
Tanguay RM (1983) Genetic regulation during heat shock and function of heat-shock proteins: a review. Can J Biochem Cell Biol 61:387-394.

Tytell M (2005) Release of heat shock proteins (Hsps) and the effects of extracellular Hsps on neural cells and tissues. Int J Hyperthermia 21:445-455.

Uffenbeck SR, Krebs JE (2006) The role of chromatin structure in regulating stress-induced transcription in Saccharomyces cerevisiae. Biochem Cell Biol 84:477-489.

Wadhwa R, Kaul SC, Ikawa Y, Sugimoto Y (1993) Identification of a novel member of mouse hsp70 family. Its association with cellular mortal phenotype. J Biol Chem 268:6615-6621.

Wadhwa R, Taira K, Kaul SC (2002) An Hsp70 family chaperone, mortalin/ mthsp70/PBP74/Grp75: what, when, and where? Cell Stress Chaperones 7:309-316.

Wang J, Koyama S, Komatsubara Y, Suzuki Y, Taki M, Miyakoshi J (2006) Effects of a $2450 \mathrm{MHz}$ high-frequency electromagnetic field with a wide range of SARs on the induction of heat-shock proteins in A172 cells. Bioelectromagnetics 27:479-486.

Wang MH, Grossmann ME, Young CY (2004) Forced expression of heatshock protein 70 increases the secretion of $\mathrm{Hsp} 70$ and provides protection against tumour growth. Br J Cancer 90:926-931.

Wang XY, Arnouk H, Chen X, Kazim L, Repasky EA, Subjeck JR (2006) Extracellular targeting of endoplasmic reticulum chaperone glucoseregulated protein 170 enhances tumor immunity to a poorly immunogenic melanoma. J Immunol 177:1543-1551.

Welch WJ (1987) The mammalian heat shock (or stress) response: a cellular defense mechanism. Adv Exp Med Biol 225:287-304.

Wikstrand CJ, McLendon RE, Friedman AH, Bigner DD (1997) Cell surface localization and density of the tumor-associated variant of the epidermal growth factor receptor, EGFRvIII. Cancer Res 57:4130-4140.

Yamazaki K, Nguyen T, Podack ER (1999) Cutting edge: tumor secreted heat shock-fusion protein elicits CD8 cells for rejection. J Immunol 163:5178-5182.

Zeng Y, Feng H, Graner MW, Katsanis E (2003) Tumor-derived, chaperone-rich cell lysate activates dendritic cells and elicits potent antitumor immunity. Blood 101:4485-4491.

Zeng Y, Graner MW, Katsanis E (2006a) Chaperone-rich cell lysates, immune activation and tumor vaccination. Cancer Immunol Immunother 55:329-338.

Zeng Y, Chen X, Larmonier N, Larmonier C, Li G, Sepassi M, Marron M, Andreansky S, Katsanis E (2006b) Natural killer cells play a key role in the antitumor immunity generated by chaperone-rich cell lysate vaccination. Int J Cancer 119:2624-2631.

Zhang H, Hu H, Jiang X, He H, Cui L, He W (2005) Membrane HSP70: the molecule triggering gammadelta $\mathrm{T}$ cells in the early stage of tumorigenesis. Immunol Invest 34:453-468.

Zheng H, Dai J, Stoilova D, Li Z (2001) Cell surface targeting of heat shock protein gp96 induces dendritic cell maturation and antitumor immunity. J Immunol 167:6731-6735. 